\title{
1. ESPECIFICIDAD DE LA EDUCACIÓN DE ADULTOS. BASES PSICOPEDAGógICAS Y SEÑAS DE IDENTIDAD
}

\author{
Óscar Medina Fernández
}

Universidad de Las Palmas de Gran Canaria

\section{INTRODUCCIÓN}

El adulto encuentra que "aquello no es exactamente lo que necesita o lo que desea, no corresponde a sus problemas inmediatos; ni los métodos de trabajo, ni los contenidos, ni los modos de evaluación le complacen. Esa Pedagogía infantil y pueril no le va". Este texto sobre la educación de adultos bien puede servirnos para plantear desde el principio un debate en el que se va a cuestionar buena parte de los postulados pedagógicos tradicionales. Su autor, el profesor Marín Ibáñez (1977: 90), hace un año aproximadamente que nos ha dejado, pero todos sabemos que muchas de sus publicaciones y conferencias versaron sobre la educación permanente y específicamente sobre las bases teóricas de la educación de adultos. En nuestro caso, reconocemos en él a uno de nuestros más entrañables mayores, que consiguió contagiarnos de la pasión que significaba para él la educación de adultos y la educación a distancia. Este trabajo para una revista de la UNED, institución en la que don Ricardo ejerció como profesor en sus últimos años, pretende ser un pequeño homenaje a un pedagogo español eminente, que supo ver el horizonte que ha venido a abrirse para la educación de adultos en nuestro país.

Entrando en el tema que nos ocupa, cuando hablamos del carácter específico de la educación de adultos, realmente ¿de qué estamos hablando? o ¿a 
qué tipo de problemas nos referimos? Es ésta una cuestión (recurrente en el campo de la Pedagogía) que ha estado presente en buena parte de las teorizaciones sobre la educación de las personas adultas y en los intentos de prescribir el tipo de prácticas educativas más convenientes para aquellos sectores de la población que han superado la edad de la adolescencia.

Si analizamos la literatura pedagógica sobre este asunto, comprobamos que, cuando se habla del carácter específico de la educación de adultos, de una $u$ otra forma, el problema que se plantea es el siguiente: ¿la práctica de la educación de adultos tiene que ser diferente de la educación que se imparte en las escuelas para niños y adolescentes? En caso de responder afirmativamente a esta pregunta, ¿cuáles son los fundamentos y las señas de identidad de esa diferencia?

En la corta historia de la educación de adultos comprobamos que, ante estas preguntas, han existido dos concepciones globales que rivalizan entre sí:

a) Una es la que considera que la educación de adultos no es otra cosa que una aplicación adaptativa de la Pedagogía general a las personas adultas. Desde este punto de vista, se supone que la acción educativa gira en torno a pautas generales que son aplicables a todas las edades. No cabe, por tanto, hablar del carácter específico de la educación de adultos, toda vez que estamos ante fenómenos educativos que representan variaciones menores de la misma especie educativa.

b) La otra concibe la educación de adultos como un saber educativo específico e idiosincrásico en el campo de las Ciencias de la Educación. Ésta es una perspectiva teórica que admite que, cuando hablamos de la educación de adultos, nos enfrentamos a un conjunto de prácticas educativas diferenciadas que podrían agruparse bajo una nueva especie educativa.

Este problema de la especificidad de la educación de adultos ha sido planteado por otros autores. En los extremos tenemos, por un lado, a Knowles (1968: 350-352 y 386; 1982: 20-23), que considera que la educación de adultos es una ciencia diferente, que denomina Andragogía, y, por otro lado, a Léon (1986: 103-106), para quien no existen diferencias importantes entre la formación que reciben los adultos y los niños (existen todavía más diferencias, según Léon, entre los adultos entre sí).

Flecha asume una posición intermedia al admitir determinadas particularidades dentro de una misma educación con elementos comunes. Fundamenta su posición, por un lado, en los fundamentos generales de toda acción educativa y, además, en otros fundamentos propios: las consecuencias de la adultez y el aprendizaje adulto, la subordinación de la actividad educativa a los roles sociales prioritarios que se asumen en la edad adulta, las características de las instituciones que proveen esta educación y el hecho de que la 
educación de adultos es una educación permanente y recurrente, a diferencia de la educación inicial para niños y adolescentes (Flecha, 1990a: 96).

Desde nuestro punto de vista, esta cuestión del carácter específico de la educación de adultos no es otra que el problema del concepto de educación de adultos. En el fondo, se trata de un problema fundamentalmente pedagógico: dilucidar qué vamos a entender por educación de adultos, cuáles son las señas de identidad de esta práctica educativa y en qué fundamentos nos basamos para afirmarlo.

Precisamente por ello y por la complejidad que supone el intento, nos inclinamos a considerar que este asunto debe ser tratado desde varios puntos de vista. Nos referimos a que la reflexión sobre los fundamentos del carácter específico de la educación de adultos (bases de la diferencia y señas de identidad), que entendemos que es una reflexión pedagógica, ha de hacerse desde una perspectiva interdisciplinar (como corresponde a muchas investigaciones pedagógicas), fundamentalmente, desde la Epistemología, la Antropología ética, la Psicología, la Sociología y, finalmente, también desde la Pedagogía.

Nuestra aportación en este trabajo se va a limitar al análisis psicológico y a la reflexión pedagógica. Desde la Psicología nos interesa delimitar qué vamos a entender por persona adulta desde el punto de vista del desarrollo psicosocial; en este caso, tratamos de identificar las características del educando, los protagonistas de la educación de adultos. Desde la Pedagogía extraemos las consecuencias que se derivan del análisis psicológico anterior, exploramos el marco teórico más general en el que vamos a situar la educación de adultos como saber educativo, definimos algunos fines que señalan el horizonte optimizante de esta práctica educativa y, también, entramos en la definición de algunas características que diferencian este sector educativo de otros.

En tal sentido, desde esta lectura psicopedagógica, podemos formular nuestra postura acerca del carácter específico de la educación de adultos en los siguientes términos, que trataremos de demostrar a lo largo de la exposición: basándonos en la investigación psicológica que actualmente tenemos disponible, y haciendo uso de determinados conocimientos pedagógicos, podemos afirmar que existen evidencias que nos permiten fundamentar algunos aspectos del carácter específico de la educación de adultos como un tipo de educación propia que se diferencia de lo que habitualmente se realiza en las escuelas para niños y adolescentes; dicho de otra manera, creemos que, en el momento presente, la segunda de las dos concepciones rivales de las que hablábamos al principio parece que se está haciendo con el triunfo.

Queremos hacer la salvedad, no obstante, de que en la medida en que limitamos nuestra aportación a una visión psicopedagógica del problema, estamos seguros de que vamos a aportar una imagen incompleta y parcial 
acerca de la especificidad de la educación de adultos. Por ello, desde esta revista, nos permitimos la libertad de invitar a otros a abordar la perspectiva epistemológica, antropológica y social, perspectivas con las que, sin duda, se completaría el vasto panorama de la señas de identidad de la educación de adultos.

\section{LA PERSONA ADULTa DESDE EL PUNTO DE VISTA PSICOSOCIAL}

El estudio de la persona adulta desde el punto de vista del desarrollo psicosocial nos va a permitir analizar, sobre todo, aquellas señas de identidad de la educación de adultos que tienen que ver con la concepción del educando, y a partir de ahí, con la función y el rol del mismo en los procesos de educación sistemática. Estamos convencidos de que la tarea de educar no es la misma según que los educandos sean niños y adolescentes (que además forman parte del sistema educativo obligatorio), o personas adultas. El hecho de considerar la adultez como un período diferenciado del desarrollo nos autoriza a definir algunas características propias que, sin duda, tendrán que afectar a las prácticas educativas en las que participen las personas adultas.

La clave que nos abre la puerta de esa nueva visión del educando de la que hablamos se encuentra en las nuevas investigaciones de los psicólogos, que en las últimas décadas han conseguido cambiar la concepción que se tenía del propio desarrollo y de la adultez.

Como muchas otras ciencias, la Psicología ha pasado por diferentes momentos históricos en los que podrían identificarse enfoques también diferentes. En relación con el desarrollo y la adultez, los historiadores de la Psicología reconocen que se han superado las concepciones mecanicistas y organicistas tradicionales y que en la actualidad parecen tener más vigencia las concepciones desarrolladas en el marco de lo que se ha denominado teorías del ciclo vital (Baltes, 1991).

Para los teóricos del ciclo vital, el desarrollo es algo más que los cambios biológicos que tienen lugar en la infancia y en la adolescencia. Lejos de ser así, el desarrollo se entiende como un complejo proceso de transformaciones que se producen a lo largo de toda la vida y que afectan a múltiples dimensiones del individuo: la dimensión biológica, por supuesto, pero también las dimensiones psicológica y socio-cultural.

Es importante este cambio en la consideración del desarrollo, toda vez que, desde este nuevo punto de vista, la edad adulta adquiere entidad propia como una etapa de la vida durante la cual se producen cambios relevantes en el desarrollo, cosa que no sucedía para las concepciones tradicionales, según 
las cuales el desarrollo sólo se concebía en términos de ganancias y se consideraba que la edad adulta era algo así como el final de ese desarrollo, un período más bien de estabilidad o también de deterioro, en el que no se producían cambios dignos de mención desde el punto de vista psicológico.

Lógicamente, desde las concepciones tradicionales, que consideran que en la edad adulta propiamente no hay desarrollo (el desarrollo, que se asocia con el crecimiento, ya ha terminado; eso es lo que significa etimológicamente adulto, crecido), en el mejor de los casos, la educación de adultos era considerada como un tipo más de educación o una mera prolongación de la educación anterior. Pero lo más grave de esta concepción es que se trata de una visión del desarrollo según la cual la niñez y la adolescencia son consideradas las etapas propiamente aptas para el aprendizaje, porque en estas etapas se producen cambios en el desarrollo dignos de mención que pueden ser optimizados desde la acción educativa. En consecuencia, durante la edad adulta, dado que no se producen cambios en el desarrollo dignos de mención, no parece que tenga sentido el aprendizaje.

Todo parece indicar que la infancia y la adolescencia eran consideradas las etapas en las que tenía más sentido la educación, no tanto en la edad adulta, y menos aún si, como dicen estos teóricos, en la adultez en lugar de desarrollo hay deterioro y además lo que es un adulto depende de lo que ha sido en la infancia. Estaba claro, según las concepciones tradicionales sobre el desarrollo, que todo el esfuerzo educativo debería centrarse en la infancia y la adolescencia, y, en todo caso, a las personas adultas habría que impartirles un tipo de educación compensatoria, reparadora de las pérdidas que se producían en la adultez.

Pero, como decíamos antes, todo esto ha cambiado. El primer cambio que se produce en la Psicología con relación a la edad adulta es, propiamente, el reconocimiento de una psicología propia de las personas adultas; ahora el desarrollo se entiende como pérdidas y como ganancias y la adultez se considera una etapa en la que se producen transformaciones psicológicas relevantes, un período de la vida (como todas las etapas del desarrollo) en el que se gana y se pierde y donde, debido a la gran plasticidad de la edad adulta, las pérdidas pueden quedar neutralizadas por las nuevas ganancias; una etapa, en suma, en la que, aunque no haya crecimiento, hay desarrollo y tiene sentido el aprendizaje que también puede ser optimizado mediante la educación.

A partir de aquí, la cuestión que a nosotros nos interesa abordar es identificar los rasgos psicológicos relativos al desarrollo que caracterizan a las personas adultas. Tales rasgos serán los que nos aporten buena parte de los fundamentos de la diferencia entre la educación de las personas adultas y otro tipo de educación.

En efecto, si consultamos la bibliografía existente (todavía escasa, lamentablemente, si la comparamos con la que hay sobre la niñez y la adolescencia) 
sobre la Psicología de la adultez, podríamos establecer algunas características propias de esta etapa tan extensa de la vida. Lo vamos a ver a continuación, pero conviene aclarar que, por las características de este trabajo, sólo podemos señalar un breve resumen (y necesariamente simplificado) acerca de los factores más relevantes del desarrollo en la edad adulta y, más concretamente, de los que tienen una especial relevancia para los procesos educativos.

\subsection{SIGNIFICADO SOCIAL DE LA ADULTEZ}

La primera cuestión que hemos de abordar es todo lo que tiene que ver con la acepción social de la adultez. Esto quiere decir que el verdadero significado de la adultez (precisamente por la importancia que en esta etapa de la vida tienen los aspectos sociales) depende de los componentes socioculturales del propio desarrollo y, al mismo tiempo, de cómo sea percibida una persona adulta en la sociedad en la que vive.

No sucede así, por ejemplo, con la infancia, que constituye una etapa del desarrollo claramente más determinada por los factores biológicos que influyen en el desarrollo. "La vida adulta -nos dice Blanco Abarca- al contrario de lo que ocurre en la niñez o incluso durante la adolescencia, está fundamentalmente marcada por acontecimientos sociales, por cambios en la estructura de roles, por demandas y exigencias que emanan no tanto de las capacidades y/o estructuras biológicas como de las consecuencias que se derivan de la asunción de importantes tareas sociales" (Blanco Abarca, 1991: 202).

A diferencia de la niñez, nos encontramos que unos factores que influyen en la percepción de la adultez son los demográficos, entre otros, la esperanza de vida o la propia estructura y la evolución de la población. Otros factores son culturales, como el tipo de influencia que los adultos tienen en la sociedad y en la vida política, los cambios en la estructura social, o también lo que viene sucediendo en las últimas décadas: la creciente preocupación de los científicos y de los medios de comunicación por la edad adulta.

Destacamos esta primera consideración de la edad adulta, como una etapa cargada de significado social, por la importancia que va a tener en la propia concepción, también social, de la educación de adultos, a lo que más adelante nos referiremos.

\subsection{EL PERÍODO MÁS EXTENSO DE LA VIDA CON TRES ETAPAS DIFERENCIADAS Y EL GRUPO SOCIAL MÁS NUMEROSO}

Hay una segunda cuestión importante que también va a resultar decisiva al hablar del alcance y la importancia de la educación de adultos en los países de 
nuestro entorno. Nos referimos a que la edad adulta, por un lado, constituye el período más extenso de la vida en el que los psicólogos reconocen etapas bien diferenciadas, y por otra parte, que las personas adultas forman el colectivo más numeroso en las sociedades modernas.

Actualmente todo el mundo descarta que la edad adulta sea una amplia etapa más o menos estable e indiferenciada. Los psicólogos de la nueva generación están convencidos de que la adultez es un período diferenciado de la vida; más aún, están persuadidos de la existencia de diferentes etapas, con significados también diferentes, que se suceden a lo largo de la vida de una persona adulta.

Con carácter general, a partir del nacimiento, el desarrollo se suele dividir en tres grandes períodos: infancia, adolescencia y adultez. Y la adultez, que es el período que nos interesa, a su vez se subdivide en tres etapas: juventud, mediana edad y vejez. En el cuadro número 1 aparecen, según diferentes autores, las tres etapas de la adultez con las referencias a las edades.

El problema es que no siempre coinciden los autores en las edades que sirven de referencia para delimitar estas tres etapas, como si los "relojes biológicos" hubiesen cambiado a lo largo de la historia. Pero lo que sucede en realidad es que el tiempo del desarrollo, sobre todo en la edad adulta, es un tiempo relativo que depende de factores sociales y culturales, razón por la cual algunos autores suelen hablar de "relojes sociales" al referirse a los momentos en los que tienen lugar los cambios en la edad adulta; estamos, por tanto, ante una cuestión claramente social y cultural que, lógicamente, ha ido cambiando con los años. De hecho, hoy día se considera jóvenes a los que llegan hasta los 40 años, pero en el pasado la barrera de los 40 era ya casi un signo de vejez.

\begin{tabular}{|l|c|c|c|c|c|c|}
\hline \multicolumn{7}{|c|}{ Elapas y años de la adultez según diferentes autores } \\
\hline \multicolumn{1}{|c|}{ Etapas } & $\begin{array}{c}\text { Erikson } \\
1981\end{array}$ & $\begin{array}{c}\text { Levinson } \\
1986\end{array}$ & $\begin{array}{c}\text { Papalia } \\
1992\end{array}$ & $\begin{array}{c}\text { Rice } \\
1997\end{array}$ & $\begin{array}{c}\text { Craig } \\
1997\end{array}$ & $\begin{array}{c}\text { Otras } \\
\text { denominaciones }\end{array}$ \\
\hline Juventud & $20-35$ & $17-40$ & $20-40$ & $20-40$ & $20-40$ & Adultez temprana \\
\hline Mediana edad & $35-65$ & $40-65$ & $40-65$ & $40-60$ & $40-60$ & $\begin{array}{c}\text { Adultez media. } \\
\text { Madurez }\end{array}$ \\
\hline Vejez & $>65$ & $>65$ & $>65$ & $>60$ & $>60$ & $\begin{array}{c}\text { Adultez avanzada. } \\
\text { Ancianidad }\end{array}$ \\
\hline
\end{tabular}

Lo mismo sucede con la vejez: su frontera para unos autores está a partir de los 60 años y para otros más allá de los 65; una cuestión que refleja en el 
fondo cómo percibe la sociedad a los viejos y cómo se sienten a sí mismos los que ya han superado la mediana edad.

Pero ya decíamos que no sólo hablamos del período más extenso de la vida de un individuo. Precisamente por ello, a diferencia de lo que venía sucediendo en épocas pasadas, en la actualidad, y sobre todo en los países desarrollados, las personas adultas también constituyen el colectivo más numeroso de la población. Según datos de la población española del año 98 (si ponemos en los 20 años la frontera que separa la adultez de las etapas anteriores del desarrollo, tal como lo hacen algunos autores del cuadro número 1) los mayores de 20 años representaban el $78 \%$ de toda la población (INE, 1998).

\subsection{CAMBIOS BIOLÓGICOS}

Los cambios biológicos, precisamente por la importancia que tienen en la edad adulta, no pueden ser ignorados por los profesionales de la educación de adultos, pues algunos de estos cambios van a afectar a los procesos de formación. Especialmente nos reférimos a los cambios biológicos que se suceden a partir de la tercera etapa de la edad adulta, durante la vejez, período de la vida en el que cada vez se incrementan más las experiencias educativas.

Desde el punto de vista biológico, la edad adulta se caracteriza por el hecho de que el crecimiento ha llegado a su término, lo que significa que la configuración orgánica del individuo se encuentra en estado de madurez. Otro de los rasgos biológicos de la edad adulta es que se trata de una etapa de la vida en la que, a partir de la mediana edad sobre todo, se aceleran los procesos de envejecimiento. Los psicólogos se refieren a esta etapa afirmando que la proporción de pérdidas puede ser superior a las ganancias, aunque, en no pocos casos, aquéllas sean neutralizadas por éstas.

Por otra parte, en relación con las capacidades físicas, como la fuerza, la velocidad y la resistencia, la edad adulta representa la etapa de la vida en la que se alcanza el punto más alto (entre los 20 y los 30 años) y, al mismo tiempo, es también la etapa (durante la vejez) en la que se produce una importante reducción de estas capacidades, aunque en este último caso se compensa con una mayor cautela y seguridad en los movimientos.

Asimismo, en la edad adulta, principalmente en la etapa de la vejez, nos vamos a encontrar con algunos cambios que pueden afectar a los procesos de formación: se agudizan los problemas en la audición (dificultad para los sonidos de alta frecuencia) y en la visión (perdida de la agudeza visual), lo que sin duda va a influir en la vida cotidiana y en la propia autoestima de quienes se encuentran con estos problemas.

No obstante, pese a estos cambios biológicos, hay que tener en cuenta que, desde la perspectiva de las teorías del ciclo vital, el desarrollo se carac- 
teriza por la multidimensionalidad y la multidireccionalidad, lo que supone una alternativa al modelo biológico anterior que veía en la edad adulta fundamentalmente una mera etapa de deterioro. El resultado de estas nuevas investigaciones es doble: por un lado, aparece el concepto de heterogeneidad como una de las características propias del desarrollo en la edad adulta, lo cual "va contra el estereotipo de que todas las personas mayores son muy parecidas"; y, por otra parte, nos encontramos con el fenómeno de la compensación, dado que "cualquier déficit, limitación o pérdida lleva en sí mismo la capacidad para generar nuevas formas de innovación y progreso" (Vega y Bueno, 1995: 30 y 31).

\subsection{CAMBIOS COGNITIVOS}

Nos hemos referido antes a que, en los últimos años, en el campo de la Psicología han cambiado las ideas y teorías acerca de las personas adultas. Un factor importante de esa evolución es el constituido por los avances de la investigación sobre la inteligencia y su desarrollo durante la edad adulta. No existe la menor duda acerca de la importancia de la inteligencia en el aprendizaje, de tal modo que sin la intervención de aquélla no conseguiríamos éste. Por esta razón, cada vez parece más claro que sobre las posibilidades de aprendizaje en la edad adulta gravita con un importante peso la concepción que se posea acerca de la inteligencia; en otras palabras, la educación de adultos será lo que den de sí las posibilidades de aprendizaje en la edad adulta y, al mismo tiempo, estas posibilidades de aprendizaje dependerán, en suma, de cuál sea el desarrollo intelectual de una persona a partir de la adolescencia.

Uno de los cambios más relevantes que se ha desarrollado a partir de las nuevas investigaciones del ciclo vital, que nos va a permitir entender el alcance de los cambios cognitivos que se producen en la edad adulta, es el habido en el propio concepto de inteligencia y el que se refiere a la negación de la hipótesis del declive, que tantos efectos negativos ha producido en la comprensión psicológica de la edad adulta y, a partir de ahí, en la propia educación de adultos.

Así pues, se ha superado la concepción clásica de la inteligencia entendida exclusivamente como el pensamiento formal basado en niveles cada vez más altos de abstracción (lo que tradicionalmente han medido los test de inteligencia), y hoy día se concibe la inteligencia desde una perspectiva mucho más amplia, como la capacidad para gobernarnos a nosotros mismos (Sternberg, 1988: 168-176; Sternberg y Salter, 1987: 17-54).

Y respecto a la evolución de la inteligencia en la edad adulta, precisamente a partir de las investigaciones sobre los cambios cognitivos más allá de la adolescencia, se reconoce que las capacidades intelectuales varían en la edad adulta, en el sentido de que se gana en algunos aspectos aunque se pier- 
da en otros por el efecto del envejecimiento. La inteligencia fluida, por ejemplo, al depender más de la base fisiológica (cuyo deterioro se percibe a partir de los sesenta años) experimenta un leve declive. Pero este declive suele ser compensado por el incremento en la inteligencia cristalizada, que depende más de la base social y del aprendizaje (Horn y Cattell, 1967: 107-129).

Por otra parte, las últimas investigaciones ponen de manifiesto que en la vida adulta, además del pensamiento formal, se utilizan otras formas de pensamiento postformal (pensamiento práctico, pensamiento dialéctico, pensamiento divergente, pensamiento flexible, etc.). No son pocos los psicólogos que abundan en esta idea de que la lógica formal no es la única que impregna el comportamiento intelectual del adulto (Cfr. León Cascón y Carretero, 1992: 497-523; Corral, 1992: 532-536; Vega y Bueno, 1995: 225-227; Clemente, 1995: 142-152; Papalia y Wendkos, 1992: 488 y 548; Craig, 1997: 488 y 565; Ceci y Liker, 1986: 119-142; García Madruga y Carretero, 1991: 143-175; Scribner, 1986: 13-30; entre otros).

En los últimos años, uno de los autores que está teniendo gran influencia en la concepción del desarrollo durante la edad adulta es Vygotski. Precisamente por ello, sus escritos están sirviendo para fundamentar algunos cambios que ahora todo el mundo reconoce en relación con el conocimiento y el aprendizaje, y, a partir de ahí, para fundamentar la dirección de algunas prácticas educativas. La tesis vygotskiana, según la cual el funcionamiento mental deriva principalmente no tanto de la maduración como de las influencias sociales y culturales, no sólo echa por tierra buena parte de los postulados tradicionales que asociaban estrechamente desarrollo mental y dotación genética, sino que abre nuevos horizontes a la hora de comprender la naturaleza de la inteligencia y el aprendizaje en la adultez. Cole y Scribner han intuido perfectamente esta trascendencia de Vygotski al afirmar acerca de su obra: "Al mismo tiempo confeccionó una crítica devastadora de las teorías que afirman que las propiedades de las funciones intelectuales adultas proceden únicamente de la maduración, o que, como mínimo, se hallan configuradas de antemano en el niño, esperando simplemente la oportunidad para manifestarse" (Cole y Scribner, 1989: 24).

En este sentido, al destacar la importancia que las cuestiones culturales y sociales tienen en el desarrollo, las teorías de Vygotski se sitúan en la misma dirección que las de los teóricos del ciclo vital. Para este científico ruso, considerado por Luria como un genio de la psicología, el pensamiento y el lenguaje están íntimamente relacionados. En contra de algunas teorías de su época que daban por supuesto que el pensamiento y la palabra eran elementos aislados e independientes, afirma que "Sería un error considerar el pensamiento y el habla como dos procesos sin relación, que corren paralelos o se cruzan en determinados puntos..." (Vygotski, 1995: 197). Así pues, en la medida en que el pensamiento depende del lenguaje, en esa medida el conocimiento y el aprendizaje dependerán de las relaciones e interacciones sociales. Se destaca aquí el carácter social del aprendizaje por su dependencia del 
lenguaje, una visión a la que se sumarán otros autores que, como veremos, están contribuyendo a identificar un tipo de aprendizaje social (un aprendizaje dialógico, basado en las habilidades comunicativas que poseen todas las personas) que va a ocupar una posición sobresaliente en la edad adulta.

Por lo que se refiere a la memoria, la experiencia demuestra que algo se pierde con la edad, pero esta pérdida afecta sólo a un tipo de memoria y para unos procesos, y no para otros. Así como la memoria sensorial y primaria no parece que pueda ser afectada por la edad, sin embargo sí suele ser afectada la memoria secundaria, que es principalmente la que interviene en los procesos de aprendizaje. Pero los estudios sobre este tema parecen demostrar que, con la edad adulta, la memoria se hace más selectiva: se pierde memoria para tareas de recuerdo, no para tareas de reconocimiento; se pierde memoria para los datos, la fechas, los hechos, los nombres, los detalles, las anécdotas, etc., pero no tanto para los significados, las ideas, las interpretaciones, los análisis y las síntesis (Palacios y Marchesi, 1991: 271-274).

\subsection{EL APRENDIZAJE EN LA EDAD ADULTA}

Por la importancia que tiene el aprendizaje en todo proceso educativo, merece la pena extenderse en este punto. Lógicamente, lo dicho acerca de la inteligencia y la memoria va a afectar a los cambios en el aprendizaje de las personas adultas. El aprendizaje es algo que está relacionado con la inteligencia y con la memoria, pero no podemos confundirlo con estas facultades. Lógicamente la capacidad de aprendizaje depende de la inteligencia en la medida en que los cambios en la inteligencia que se producen a lo largo del desarrollo afectan al aprendizaje; asimismo, el tipo de aprendizaje que se produce en la edad adulta (donde la experiencia y la inteligencia cristalizada juegan un papel fundamental) no es equiparable al que se produce en la edad infantil (época en la que las operaciones concretas ocupan un lugar relevante).

Por otra parte, es evidente la relación entre memoria y aprendizaje, aunque tampoco podemos confundir ambas facultades. Está claro que, si no se aprende, nada hay que recordar; pero, si la memoria no es suficiente, poco podemos aprender. El aprendizaje, guiado por la inteligencia, se refiere a las nuevas adquisiciones de conductas o conocimientos, y la memoria lo que hace es almacenar esas nuevas adquisiciones para hacer uso de ellas y poder recuperarlas en el momento preciso.

En efecto, el aprendizaje, vehiculado por la inteligencia y apoyado por la memoria, está más relacionado con esas nuevas adquisiciones de las que hacemos uso a lo largo de nuestra vida, adquisiciones que se supone que optimizan al ser humano, lo mejoran más allá de su propio desarrollo biológico y genéticamente condicionado. En general coinciden los autores en afirmar que el aprendizaje es una de las facultades humanas más complejas, difícil de identificar en todos sus elementos y nada sencillo de medir y ana- 
lizar. Se aprende en la infancia y se aprende en la edad adulta, y en ambos casos puede haber procesos implicados que sean similares, pero lo que a nosotros nos interesa es destacar las diferencias cualitativas que se producen en el aprendizaje durante la edad adulta, aunque tengamos que reconocer de antemano que, por el momento, son pocas las investigaciones referidas al aprendizaje en la edad adulta, sobre todo si las comparamos con las que existen sobre el aprendizaje en la infancia.

Teniendo en cuenta la bibliografía que hemos consultado, tendríamos que decir que las investigaciones sobre el aprendizaje en la edad adulta, aunque prometedoras, por el momento no nos permiten establecer suficientes normas pedagógicas específicas o criterios propios que los educadores puedan aplicar en los procesos de enseñanza-aprendizaje con las personas adultas. Desde nuestro punto de vista, esto tiene que ver con la marginación que tradicionalmente ha padecido la educación de adultos y con la escasez de investigaciones que se han realizado de momento en este sector de la educación. Además, los que trabajamos en este campo sabemos que, en muchos casos, investigaciones realizadas con niños se han elevado a una categoría general y, sin más, se han extrapolado también a los adultos.

Otras veces constatamos que no pocas conclusiones sobre el aprendizaje se han realizado en situaciones casi de laboratorio y son el fruto de investigaciones, unas veces, sin sentido, y otras, con un enfoque escolar, en las que la tarea consiste, por ejemplo, en aprender pares de palabras asociadas o no asociadas, palabras seriadas, presentación de estímulos y petición de recuerdos, diferentes ritmos en la presentación de estímulos, etc. En suma, son pocas las investigaciones basadas en las situaciones normales de la vida diaria en las que una persona adulta aprende: en su trabajo, en su familia, a lo largo de sus actividades sociales, o cuando expresamente participa de actividades formativas más sistemáticas, etc.

Las primeras investigaciones sobre el aprendizaje en la edad adulta, como ya ocurriera con la inteligencia y con la memoria, se han centrado más en su medida que en la comprensión de su naturaleza. Así nos encontramos investigaciones que se han ocupado de medir el aprendizaje y compararlo con el de los más jóvenes. Y nuevamente sucede, como con las mediciones de la inteligencia, que los resultados de la comparación aparecen claramente afectados por la metodología empleada. En general, cuando las pruebas que tratan de medir la capacidad de aprendizaje se basan en materiales carentes de sentido los jóvenes salen mejor parados; por el contrario, con materiales dotados de sentido no se aprecian diferencias significativas entre los jóvenes y los mayores.

La bibliografía que sobre este asunto ha consultado Úrsula Lehr le ha permitido resumir las principales conclusiones sobre la capacidad de aprendizaje de los mayores. Según el resumen de Lehr (1979: 103-105), las investigaciones que se han ocupado de comparar la capacidad de aprendizaje de los mayores con la de los más jóvenes, ponen de manifiesto que las diferencias 
dependen, no tanto de la edad, sino más bien de otros factores que agrupamos en dos categorías:

a) Factores relacionados con la naturaleza de la prueba. Por ejemplo, si las pruebas están provistas de sentido, los resultados de los mayores son equiparables a los de los jóvenes; cuando se elimina la velocidad de los resultados de la prueba, se nivelan las diferencias; si hay entrenamiento previo a las pruebas, se reducen las diferencias; si el material de las pruebas se presenta ordenado se aprende mejor. Pero las pausas intercaladas en la prueba dificultan los resultados de los mayores, no así los de los más jóvenes. Por otra parte, parece que también el tipo de aprendizaje influye en los resultados: el aprendizaje por partes favorece a los jóvenes y el aprendizaje global a los viejos.

b) Factores propios de cada sujeto. Entre otros, la salud, la seguridad, la dotación inicial de partida, la práctica y la familiaridad con el tipo de pruebas, la motivación y el uso de técnicas de aprendizaje, el origen social, la formación escolar previa, el tipo de profesión, etc.

Algunos autores, con mucho sentido, han tratado de extraer conclusiones pedagógicas a partir de las investigaciones sobre el aprendizaje. Este es el caso, por ejemplo, del psicólogo alemán Löwe (1970; en Lehr, 1979: 107-109), que ha tratado de aplicar a la pedagogía de adultos los conocimientos científicos procedentes de la investigación sobre el aprendizaje. Así establece una serie de principios útiles para la formación de las personas adultas, afirmando que el aprendizaje se favorece, entre otras, en las siguientes condiciones:

a) Si hay actividad durante el proceso de aprendizaje.

b) Si el que aprende analiza la situación.

c) Si se va obteniendo información acerca de los resultados del aprendizaje.

d) Si esa información se proporciona lo más rápidamente posible.

e) Si se refuerza de forma constante el aprendizaje deseado.

f) Si se eliminan los refuerzos del aprendizaje no deseado.

g) Si se realizan los ejercicios y repeticiones necesarios para cada aprendizaje.

h) Si se eliminan el miedo y la ansiedad.

Pero, en nuestra opinión, tales principios, vistos en su conjunto, no son otra cosa que las conocidas y clásicas leyes del aprendizaje, de orientación en 
su mayoría conductista, algunos de los cuales tienen, incluso, su origen en la experimentación con animales. El problema es que no podemos afirmar que tales principios sean especialmente importantes para el aprendizaje de las personas adultas. Más exacto sería afirmar que tales postulados son principios generales del aprendizaje y, por tanto, válidos y aplicables para los adultos, pero también para los niños.

Nuevamente observamos que apenas existen investigaciones específicas sobre el aprendizaje en la edad adulta que nos permitan potenciar, mejorar y desarrollar los procesos de educación más allá de la adolescencia. Ya hemos comentado antes que, en este caso, los investigadores (como ha sucedido también en la investigación sobre la inteligencia y la memoria) han estado más empeñados en medir y comparar el aprendizaje que en comprender y analizar su naturaleza.

Con todo, algunos autores han comprendido las necesidades específicas que tienen los educadores de adultos y han asumido el reto de aportar elementos diferenciales de lo que podría ser una pedagogía sobre el aprendizaje de las personas adultas. En este sentido, Rice (1997: 555), basándose en investigaciones más recientes, propone una selección de principios encaminados a mejorar el aprendizaje en la edad adulta. Aunque algunos de los principios de Rice ya están implícitos en las leyes del aprendizaje señaladas anteriormente por Löwe, no obstante conviene que reseñemos los que nos han parecido más importantes:

a) Es necesario eliminar la ansiedad en relación con la eficiencia y los resultados.

b) Los adultos necesitan tener la oportunidad de expresar lo que saben.

c) El desempeño de las personas adultas es mayor con tareas que resulten relevantes y posean sentido para ellas.

d) La información que se organiza en categorías, con secuencias lógicas y agrupada en asociaciones significativas, se aprende mejor.

e) La motivación mejora cuando comprenden la relevancia o la aplicación de lo que han de aprender.

f) El ritmo de ejecución de las tareas debe permitir un desempeño óptimo, dado que se valora más la precisión en el desempeño que la rapidez.

g) Otras investigaciones parecen demostrar que el aprendizaje de las personas adultas mejora si se repite la tarea, si se expone en voz alta, si se eliminan las interferencias, si la información se presenta a través de varios sentidos y si el sujeto no se encuentra fatigado. 
Un especial interés tienen en este sentido algunos trabajos que se están desarrollando en el campo de la educación de adultos con la finalidad de aportar orientaciones específicas para el aprendizaje en la edad adulta. Entre otras, se conocen las investigaciones de Brockett e Hiemstra (1993) sobre el aprendizaje autodirigido, basado en la responsabilidad y en la madurez de las personas adultas. En tal caso, sí que reconocemos aquí orientaciones específicas que, además, se basan en investigaciones realizadas con personas adultas. Hay que tener en cuenta que en la edad adulta existen condiciones psicológicas más que suficientes para el autoaprendizaje, toda vez que, entre los rasgos psicológicos de las personas adultas, como luego veremos, destaca la autonomía en la toma de decisiones y la capacidad para asumirlas responsablemente.

En nuestro país se conocen algunas experiencias basadas en el autoaprendizaje; una de ellas es la del centro de educación de adultos La Concordia, de Sabadell (Barcelona). Según Margarida Massot (1997: 20-29), que colabora en el centro de La Concordia, se trata de dedicar un espacio para el aprendizaje autónomo de los alumnos, pero integrado en el currículo del centro; para que este aprendizaje autónomo sea posible, el centro cuenta con unos recursos propios y materiales didácticos, así como con el asesoramiento de unos profesores que dedican parte de su horario al espacio de autoformación.

En relación con el aprendizaje en la edad adulta, no podemos ignorar otros trabajos de interés: los estudios de Saddington (1998), Bond y Wilson (1998) sobre aprendizaje experiencial a través de la comunicación y la reflexión personal; los trabajos de Rogers y Freiberg (1996) sobre la facilitación del aprendizaje en un clima de libertad y compromiso; las aportaciones de Verner (1964) sobre la jerarquía de roles en relación con los aprendizajes en las diversas edades que revelan el diferente uso del tiempo que las personas adultas dedican al aprendizaje.

Una investigación que se realiza en España sobre el aprendizaje adulto es la de Ferrández, Gairín y Tejada (1990) donde tratan de indagar, por un lado, la relación existente entre las características personales del adultos y sus preferencias didácticas $\mathrm{y}$, por otro, el modo en que el contexto de aprendizaje puede condicionar la relación entre los agentes del acto educativo.

Especialmente sobre la participación de los ancianos en procesos de aprendizaje merece atención el trabajo de Martín García (1994), que analiza la especial incidencia que tiene en estos procesos la propia actitud hacia la participación y sobre todo el concepto de sí mismo, que acaba convirtiéndose en un factor decisivo para el establecimiento de relaciones interpersonales.

En la dirección de escudriñar los elementos diferenciales también están trabajando García García y sus colaboradores (García García et al. 1998a: 123). Convencidos de la diferencia que experimentan las personas adultas 
respecto a los niños cuando se enfrentan a la labor de aprender, en la revisión bibliográfica que han hecho han encontrado diferencias importantes entre el aprendizaje de los adultos y el de los niños y adolescentes. Por ejemplo, los adultos perciben el proceso de aprendizaje como una contribución valiosa para su desarrollo, tienen ideas más claras sobre qué es importante aprender, perciben el tiempo de forma diferente a los niños, su experiencia les permite conectar mejor los nuevos aprendizajes, son más críticos respecto a las informaciones que contradicen su experiencia, las motivaciones son más intrínsecas, en los procesos de enseñanza reclaman un trato más igualitario, están más orientados a los problemas que a las materias, etc.

Más concretamente, en relación con el abandono de las enseñanzas, estos autores han encontrado dos principales razones que parecen explicar los motivos que están en la base de algunos abandonos por parte de las personas adultas: por un lado, la inadaptación escolar que experimentan en el proceso de enseñanza aprendizaje (sentimientos de inseguridad, falta de dedicación, etc.); y por otra parte, razones extraescolares (problemas económicos, familiares, etc.). Según su opinión, estos dos motivos diferentes de abandono de las enseñanzas están generando perfiles diferenciados de alumnos adultos ante los procesos educativos que, al mismo tiempo, reclaman un modelo educativo diferente (García García et al., (1998b: 144-150).

Pese a la importancia que sin duda tienen las anteriores contribuciones teóricas, consideramos que las propuestas más elaboradas acerca del aprendizaje en la edad adulta son de Freire (1992). Sus aportaciones sobre el aprendizaje dialógico, aunque aparecen en casi todos sus libros, de forma más explícita cruzan transversalmente su obra más importante, Pedagogía del oprimido, a medida que se van articulando los supuestos y componentes de su teoría sobre la educación liberadora como un tipo de educación que se opone a la educación bancaria. Para este pedagogo brasileño, el aprendizaje resulta emancipador (es decir, liberador, optimizador) si la acción educativa es problematizadora y esperanzadora, lo que sólo es posible mediante el diálogo intersubjetivo e igualitario entre educadores y educandos.

Conviene destacar que el interés de la propuesta de Freire sobre el aprendizaje dialógico no sólo reside en las ventajas que tiene el diálogo como un medio efectivo para el aprendizaje (lo que además han venido a demostrar los psicólogos sociales con las técnicas de grupo); más importante resulta todavía el modo en que sitúa el diálogo (y sus características) en el centro de gravedad de los procesos de aprendizaje, como condición ineludible para que la acción educativa sea crítica y transformadora.

En base a las teorías de Freire, desde hace años vienen trabajando los miembros del Centro de Investigación en Educación de Personas Adultas (CREA, según las siglas en catalán) de la Universidad de Barcelona. Este grupo, específicamente dedicado a la investigación de la educación de adultos, está interesado en estudiar las consecuencias educativas que se derivan 
de la concepción dialógica del aprendizaje de Freire que a su vez encuentra su base en la teoría de la acción comunicativa de Habermas. Flecha, fundador de CREA, hace poco ha publicado un libro sobre este tema titulado Compartiendo palabras, donde, además de desarrollar esta teoría sobre el diálogo en relación con el aprendizaje, relata diferentes experiencias de quienes han conseguido importantes aprendizajes a lo largo de su vida. Precisamente por ello, subtitula su libro El aprendizaje de las personas adultas a través del diálogo (Flecha, 1997).

Según Flecha, el aprendizaje dialógico es un tipo de aprendizaje global que se basa en la comunicación y en el lenguaje como medio de entendimiento; además es un tipo de aprendizaje válido para una gran diversidad de contextos y se basa en siete principios (Flecha, 1977: 13-46):

1) Principio del diálogo igualitario. Según Flecha, "el diálogo es igualitario cuando considera las diferentes aportaciones en función de la validez de sus argumentos, en lugar de valorarlas por las posiciones de poder de quienes las realizan" (p. 14). Por ello, este contexto de igualdad representa la primera condición para el aprendizaje que, precisamente por la igualdad y la validez de los argumentos, genera aprendizaje tanto en el alumno como en el profesor y lo hace con más profundidad que las formas tradicionales de enseñanza.

2) Principio de la inteligencia cultural. En franca oposición a las teorías tradicionales sobre el déficit de la edad adulta, según este principio, "todas las personas tienen las mismas capacidades para participar en un diálogo igualitario, aunque cada una pueda demostrarlas en ambientes distintos" (p. 20). En tal sentido, el concepto de inteligencia cultural se basa en las habilidades comunicativas que poseemos todos los seres humanos, lo que nos permite resolver problemas académicos y prácticos.

3) Principio de transformación. "El aprendizaje dialógico transforma las relaciones entre la gente y su entorno" (p. 28). Esta es una idea ampliamente desarrollada por Freire que, al igual que otros autores (Habermas, Giddens, Apple, Giroux, Macedo, etc.), se distancia de quienes ven la acción educativa en términos puramente reproduccionistas, como si los alumnos fuesen meras víctimas de las estructuras y no sujetos racionales, capaces de conocer y actuar, es decir, capaces de una acción transformadora.

4) Principio de la dimensión instrumental. Es importante este principio toda vez que tradicionalmente se ha creído que el aprendizaje dialógico se opone al aprendizaje instrumental. Lejos de ser así, insiste Flecha en que "El aprendizaje dialógico abarca todos los aspectos que se acuerdan aprender. Incluye, por tanto, el aprendizaje instrumental de aquellos conocimientos y habilidades que se considera necesario 
poseer. El dialógico no se opone al instrumental sino a la colonización tecnocrática del aprendizaje" (p. 33). La clave, por tanto, no está en la naturaleza (supuestamente diferente del aprendizaje dialógico frente al instrumental), sino en situarlos en el adecuado contexto de diálogo que, si además es igualitario, fomenta la reflexión.

5) Principio de la creación de sentido. Para no ser colonizados ni alienados, el aprendizaje tiene que dotar de sentido a nuestra vida. Y en el mundo de la enseñanza, esto sólo es posible mediante el aprendizaje dialógico, es decir, si la comunicación entre todos los participantes es abierta e igualitaria. "Del diálogo igualitario entre todos es de donde puede resurgir el sentido que oriente los nuevos cambios sociales hacia una vida mejor" (p. 35).

6) Principio de solidaridad. Según este principio, en el terreno de la educación no caben las posiciones nihilistas de los postmodernos, ni el neutralismo virginal de los ingenuos. Flecha cita al respecto una frase de Freire (1997) en A la sombra de este árbol: "una de las tareas más importantes para los intelectuales progresistas es desmitologizar los discursos postmodernos sobre lo inexorable de esta situación" (p. 39). En el fondo el principio de solidaridad postula que la emancipación es posible cuando es fruto de la comunicación y del apoyo mutuo. $O$ dicho de otra forma: que la comunidad es el verdadero espacio para la solidaridad entre los participantes del proceso de aprendizaje.

7) Principio de igualdad de diferencias. El aprendizaje dialógico, basado en la igualdad, debe ser complementado con este otro de igualdad de las diferencias (unidad en la diversidad, según Freire), entendiendo por ello que "la verdadera igualdad incluye el mismo derecho de toda persona a vivir de forma diferente" (p. 42). Desde el punto de vista de los contenidos del aprendizaje, más que adaptar el currículo al entorno (que, en algunos casos, podría agudizar las desigualdades), lo que hay que hacer para mejorar el aprendizaje es transformar también el entorno, convirtiendo los centros educativos en comunidades de aprendizaje.

Otro de los componentes del grupo CREA, Ana Ayuste (1999), recientemente ha defendido su tesis doctoral y en ella abunda en esta misma idea del aprendizaje dialógico, tratando de fundamentar esta concepción interactiva del aprendizaje en los postulados de Habermas, Bruner, Piaget, Vygotsky, Chomsky y del propio Freire. Según Ayuste, el aprendizaje de las personas adultas tendrá efectos emancipadores si, por una parte, se concibe que las personas adultas son capaces de conocer, aprender y participar; y por otra parte, si se utiliza el diálogo entre los participantes como el medio más adecuado para el desarrollo del conocimiento, la adquisición de competencias y el cambio social (Ayuste, 1999: 377-383). 
En resumen, a partir de lo dicho hasta ahora ¿qué podemos concluir acerca del aprendizaje en la edad adulta? También lo podemos plantear de este otro modo: ¿qué cuestiones importantes debe tener en cuenta un profesor para promover y mejorar el aprendizaje de las personas adultas? Debe quedar claro que nos referimos a las personas adultas que deciden participar en algún proceso sistemático y relativamente largo de formación; por ejemplo, quienes en una empresa asisten a actividades formativas para mejorar sus competencias laborales, o los adultos que no tienen el título de Formación Básica y asisten a un centro a recibir este tipo de enseñanzas, o quienes teniendo más formación desean acceder a otros niveles del sistema educativo, etc.

Presentamos a continuación algunas conclusiones que nos parecen relevantes acerca del aprendizaje en la edad adulta. Aunque estamos convencidos del carácter específico que tiene el aprendizaje en esta edad, las conclusiones que exponemos a continuación deben ser consideradas como provisionales o, en todo caso, como hipótesis de trabajo que podrían ser objeto de investigaciones posteriores. Por supuesto, para elaborar estas conclusiones, nos basamos en la bibliografía citada anteriormente; pero no sólo, también hemos tenido en cuenta para hacer este resumen nuestra propia experiencia de formador de personas adultas y algunas investigaciones en las que estamos trabajando (Medina, 1998, 2000). Creemos que la mayoría de las cuestiones a las que nos vamos a referir son específicas de las personas adultas, aunque algunas se refieren por igual a todas las edades, pero con un especial significado durante la adultez.

a) Carácter propio y relevancia del aprendizaje en la edad adulta. Nos parece que ésta debe ser la primera de las conclusiones a señalar. Aunque tradicionalmente el aprendizaje se ha centrado en las edades escolares y la mayoría de los profesores están acostumbrados a pensar en el aprendizaje de los niños y adolescentes, todo parece indicar que no es lo mismo aprender en la edad adulta que antes de esa edad. Es más, en contra de lo que se creía en épocas pasadas, las investigaciones desarrolladas por los teóricos del ciclo vital ponen de manifiesto que el aprendizaje se sitúa en el primer plano de la vida de una persona adulta: está demostrado que se aprende a lo largo de toda la vida.

b) Reconocimiento de la capacidad de aprendizaje de las personas adultas. Una vez establecido el carácter propio y la relevancia del aprendizaje en la edad adulta, la primera condición para que tenga lugar el aprendizaje en la edad adulta afecta a la idea que los profesores tienen de sus propios alumnos: es necesario e ineludible estar convencido de que las personas adultas son capaces de aprendizaje, lo que significa que tienen la capacidad de conocer y de actuar mejorando sus propias condiciones personales y sociales. Se trata de una concepción del educando alejada de las teorías del déficit o de los modelos compensatorios de educación. Es ésta una idea que tiene que traducirse (tras irse construyendo) en una sincera y cabal confianza de los educadores hacia los educandos. 
c) Confianza de las personas adultas en sus propias capacidades de aprender. Relacionada con la anterior hay una segunda condición que esta vez afecta a la confianza de los alumnos, o a la imagen que los educandos tienen de sí mismos (imagen que, por otra parte, puede depender de la que sobre ellos posea el educador). En este sentido, hay que tener en cuenta que, en no pocas ocasiones, la programación o los propios contenidos de las enseñanzas tendrían que ceder ante los problemas personales de merma de la confianza o escasa autoestima que, de no resolverse, dificultarían sobremanera cualquier proceso de aprendizaje.

d) Actividad y aprendizaje. Establecida esta confianza inicial tanto en el profesor como en el educando, todos los manuales sobre el aprendizaje destacan la importancia que tiene la actividad como un elemento esencial del aprendizaje; es más, si la actividad acaba en algún producto (un esquema, un resumen, unos problemas resueltos, una acción concertada, etc.), mejor aún. No en vano el propio concepto de aprendizaje se asocia a los cambios que se producen en el individuo como consecuencia de la práctica.

e) Motivación para aprender y edad adulta. Además de la actividad, la motivación es otro de los pilares del aprendizaje. Si no se está motivado difícilmente germinará el aprendizaje. En el caso de las personas adultas la motivación suele estar asegurada, toda vez que cuando un adulto decide participar en algún proceso de formación suele hacerlo de forma voluntaria. El problema, con todo, está en el mantenimiento de la motivación inicial, y en este sentido existen factores que pueden contribuir a ello: mejorar la autoestima, eliminar el miedo y la ansiedad, percibir los resultados, aplicar los aprendizajes a la vida diaria, tener oportunidad de expresar lo aprendido, etc.

f) Aprendizaje y organización de la información. Aunque la motivación sea elevada, el aprendizaje no se consolida ni se hace duradero si la información (los contenidos del aprendizaje) no se procesa convenientemente. En este sentido no son pocos los autores que señalan la necesidad de organizar la información (estructurarla, secuenciarla, relacionarla, etc.) para que pueda ser procesada y almacenada en la memoria.

g) Experiencia y encuentro de culturas. Otro aspecto importante a considerar es que las personas adultas se enfrentan a los procesos de aprendizaje desde una experiencia que han acumulado durante años. En virtud de esta experiencia las personas adultas, aunque decidan aprender, ya tienen unos comportamientos consolidados, poseen una personalidad madura y estructurada, hacen uso de sus responsabilidades familiares y laborales, aprecian lo que consideran valioso y verdadero. En suma, en algunos campos han adquirido unos conocimientos y habilidades que, a veces, no poseen ni los propios profesores. En este sentido, el aprendizaje en la edad adulta, más que un proceso de aculturación por el que alguien aporta su cultura a otros, habría que considerarlo como un encuentro de culturas, la de los alumnos y los profesores. 
h) La experiencia como fuente de aprendizaje y de conocimiento. Por otra parte, desde el punto de vista del aprendizaje, la experiencia va a desempeñar una función importante en las personas adultas: facilita el procesamiento de la información al permitir establecer relaciones significativas entre los nuevos aprendizajes y los que ya se poseen a través de la experiencia; en este sentido, podemos decir que la experiencia funciona como fuente de aprendizaje. Pero la experiencia, además de funcionar como una fuente de aprendizaje, en el caso de las personas adultas funciona también como una fuente de conocimiento, toda vez que la experiencia previa va a operar como un elemento de contraste o de validación acerca de los conocimientos nuevos que están presentes en todo proceso de aprendizaje. Esto en la práctica va a significar que las personas adultas van a estar comparando constantemente los nuevos conocimientos con la práctica y con la experiencia propia, lo que les hace ser más críticos con las informaciones que pudieran contradecir esa experiencia o sus propios valores.

i) Adultez y aprendizaje sobre problemas. En la edad adulta el aprendizaje se realiza sobre problemas. Precisamente por la experiencia, y teniendo en cuenta las responsabilidades sociales, laborales y familiares, no tiene sentido en la edad adulta un aprendizaje meramente académico y formal basado en las materias o asignaturas clásicas. Más bien el aprendizaje hay que concebirlo como un medio, más próximo o más remoto, pero siempre para abordar y enfrentarse mejor a los problemas de su vida cotidiana, familiar, social y laboral.

j) El tiempo de aprendizaje. El tiempo para el aprendizaje es un factor a considerar en el campo de la educación de las personas adultas. El aprendizaje para un adulto es una actividad secundaria. Las personas adultas tienen unas responsabilidades, lo que significa que, en primer lugar, son padres, empleados, empresarias, líderes, esposas, etc. y, secundariamente, son alumnos. El aprendizaje, por tanto, ocupa un segundo, tercero o cuarto lugar en sus vidas; no cabe pensar que se dediquen al aprendizaje a tiempo completo, como se dedicaría un escolar.

k) Aprendizaje dialógico. A partir de las aportaciones iniciales de Freire, en los últimos años se han publicado algunos estudios que vienen a poner de manifiesto la importancia que cada vez más tiene la participación y el diálogo como un medio privilegiado de aprendizaje entre adultos. En este sentido se habla del aprendizaje dialógico, o del aprendizaje en grupo, como medios que tienen dos efectos complementarios: por un lado, facilitan el aprendizaje y consolidan los compromisos sociales; y, por otra parte, mejoran la autoestima e incrementan la motivación.

l) Procesos de autoaprendizaje. Finalmente hay una cuestión que en el campo de la educación de adultos debe presidir cualquier acción formativa: los procesos de autoaprendizaje. En la edad adulta existen condiciones más que suficientes para el autoaprendizaje, toda vez que, entre los rasgos psico- 
lógicos de las personas adultas, destaca la autonomía para la toma de decisiones y la capacidad para asumirlas responsablemente. Ello significa que el proceso de aprendizaje no puede ser producto sólo de la heteroenseñanza del profesor: también tiene que ser fruto del autoaprendizaje de los propios participantes. Evidentemente no se trata de hacer del autoaprendizaje una panacea, pero tampoco el aprendizaje de un adulto puede llevarse a cabo al margen de sus rasgos psicológicos. En todo caso, el equilibrio en la combinación de heteroenseñanza, por un lado, y autoaprendizaje, por otro, es lo que podría aportar altos rendimientos para el aprendizaje de las personas adultas.

Más adelante, cuando hablemos de las señas de identidad de la educación de adultos y sobre su carácter específico volveremos, como no podía ser de otra manera, sobre buena parte de lo dicho acerca del aprendizaje. Pero repetimos lo ya dicho: que estas últimas consideraciones, más que conclusiones cerradas sobre el aprendizaje en la edad adulta, habría que considerarlas como orientaciones para la práctica (todavía abiertas y provisionales) que, en todo caso, podrían ser objeto de un análisis y debate más detenido.

\subsection{LOS CAMBIOS DE LA PERSONALIDAD EN LA EDAD ADULTA}

Al hablar de la personalidad nos referimos a una serie de cambios que se producen a lo largo del desarrollo, y que tienen que ver con una serie de cuestiones: los sentimientos y las vivencias, las relaciones afectivas y sociales, el desarrollo del yo, los estados de bienestar, la autoestima, los niveles de autonomía y de compromiso, la capacidad para asumir las propias decisiones y acciones, la estabilidad emocional, la capacidad para enfrentarse a los cambios y a las adversidades, la resistencia a la frustración, etc.

En este sentido, las investigaciones que han indagado en la personalidad adulta en general (Erikson, 1981; Levinson, 1978; Greene, Wheatley y Aldava, 1992, en Rice, 1997; Fried, 1967 en Clemente, 1996; Helson y Wink, 1992; Zirkel, 1992), así como los autores que comentan la amplia bibliografía que han consultado sobre la personalidad en la edad adulta (Blanco Abarca, 1991; Silvestre et al., 1996; Rice, 1997; Papalia y Wendkos, 1992; etc.) confirman fundamentalmente estos rasgos principales:

a) Estabilidad emocional. Las personas adultas suelen ser percibidas como individuos que viven con una cierta estabilidad emocional, entendiendo por ello una madurez y control suficiente para afrontar adversidades y ajustarse a las inevitables frustraciones que suceden en toda vida.

b) Autonomía para la toma de decisiones y para la acción. Éste es otro de los rasgos personales que se adquieren en la edad adulta. Las personas 
adultas suelen romper los vínculos de dependencia que mantenían en las edades anteriores. Con el paso de los años la incipiente autonomía se va tornando en independencia de juicio, emancipación económica, y sobre todo, en libertad para la toma de decisiones y para la acción, así como también en un mayor control de la propia vida y de su dirección.

c) Identidad personal. Por otra parte, superadas las turbulencias propias de la adolescencia, durante la edad adulta se avanza cada vez más en la identidad personal. Esta es otra característica de la personalidad adulta, y supone un mayor incremento del conocimiento de sí mismo y avanzar en la definición de rasgos propios, que, a su vez, facilita la posibilidad de establecer relaciones de intimidad con los otros.

d) Responsabilidad. Ser adulto significa también que se posee la madurez y la capacidad suficiente para hacerse responsable de las decisiones y de las acciones. Precisamente por su nivel de desarrollo racional y por su autonomía, las personas adultas pueden responder de sus pensamientos y de sus actos, razón por la cual la sociedad confía en las personas adultas y les encomienda el ejercicio de determinadas funciones sociales.

e) Participación social. Convertirse en una persona adulta pasa por un complejo proceso de socialización que lleva consigo aprender normas y valores sociales, compartir con los otros experiencias y sentimientos, y responder también a los requerimientos del grupo de referencia. La participación social se convierte así en uno de los factores determinantes de la vida de un adulto, cuyas relaciones sociales no sólo se convierten en una fuente de satisfacciones personales, sino que son también una ocasión para el compromiso y la solidaridad.

\subsection{LOS CAMBIOS SOCIALES EN LA EDAD ADULTA}

Durante la edad adulta también se van a producir importantes cambios sociales que, sin duda, tendrán una importante repercusión en otras muchas dimensiones del desarrollo y especialmente en la personalidad y en los propios sentimientos de bienestar. A estos cambios se refieren algunos autores, como Havighurst (1953 y 1972), Neugarten (1968), Rice (1997) cuando hablan de tareas de desarrollo, entendiendo por ello los retos a los que la mayoría de los individuos adultos se tiene que enfrentar durante cada etapa de su vida.

Según los estudiosos de estos temas, se supone que si tales tareas se cumplen, la edad adulta se convierte en una fuente de satisfacción y bienestar; de lo contrario, la adultez se puede convertir en una etapa de estancamiento y desilusión crecientes. El significado que tienen estas tareas de desarrollo es 
diferente según se trate de una u otra etapa (juventud, madurez y vejez). Seleccionamos a continuación algunos cambios sociales o tareas de desarrollo que funcionan como retos durante el largo período de la edad adulta:

a) Consolidar una profesión y encontrar satisfacción en ella.

b) Ajustarse a los cambios en relación con el trabajo (empleo inestable, desempleo, jubilación, etc.).

c) Establecer relaciones de intimidad y seleccionar una pareja.

d) Establecer una nueva residencia y asumir la responsabilidad del hogar.

e) Formar una familia y asumir nuevos roles: padre o madre, abuelos, etc.

f) Formar parte de grupos sociales compatibles y de redes para disfrutar del tiempo libre.

g) Participar en la vida social y cultural, asumiendo la responsabilidad cívica de los adultos.

h) Ir ajustándose a los cambios físicos propios del envejecimiento.

i) Ajustarse a los nuevos roles: abuelo, jubilado, viudo, etc.

De alguna manera, podemos decir que estos retos o aprendizajes sociales que tienen lugar a lo largo de la vida de una persona adulta se desarrollarán con éxito o no, dependiendo del modo en que se hayan consolidado los cambios en la personalidad de los que anteriormente hemos hablado.

\section{ACERCA DE LAS SEÑAS DE IDENTIDAD DE LA EDUCACIÓN DE ADULTOS}

Hasta aquí hemos hecho un análisis psicológico; a partir de ahora, entraremos en la perspectiva propiamente pedagógica. Como ya hemos dicho al principio de este trabajo, la visión pedagógica del problema de la especificidad de la educación de adultos es interdisciplinar, aunque nosotros, aun a riesgo de presentar una visión parcial de este problema, por el momento sólo haremos uso de la información psicológica obtenida y de la reflexión pedagógica.

También hemos dicho al comienzo que el problema que aquí tratamos no es otro que el de dilucidar qué vamos a entender por educación de adultos. 
Cabe suponer que, si la educación de adultos ha de ser un tipo de educación que tenga sus propias señas de identidad, o su carácter específico, ello dependerá de cómo la expresión sustantiva, educación, que es lo común, se modifique en función de la expresión determinante o su complemento, de adultos, que es lo específico; o mejor dicho, de cómo la expresión adultos (ser una persona adulta) afecta a la práctica educativa y, con ello, al propio concepto de educación. Así pues, si en el apartado anterior, aunque de forma inevitablemente simplificada, hemos tratado de resumir lo que significa ser una persona adulta, ahora nos interesa entrar en la combinación de ambas expresiones (educación y persona adulta), a ver si de la relación entre ellas se derivan consecuencias para la expresión sustantiva, la educación.

Situados en la reflexión pedagógica, creemos que una forma de abordar este problema del concepto de educación de adultos y, a partir de ahí, el de sus señas de identidad, es tratar de centrarse fundamentalmente en dos rasgos de la acción educativa que parecen concitar bastante adhesión entre los teóricos de la educación: uno, que la educación es un proceso de aprendizaje; el otro, que la educación tiene que ser optimizante para los seres humanos (Sanvisens, 1983; Martínez, 1986).

Si esto es lo que entendemos por educación, cabe pensar lógicamente que también lo será la educación de adultos. Es decir, si entendemos la educación como un proceso de aprendizaje que tiene efectos optimizantes en sus protagonistas, lógicamente, también lo será la educación de las personas adultas. Dicho de otro modo, esto sería lo que la educación de adultos tiene en común con otro tipo de educación, o mejor, lo que todas las acciones educativas tienen en común.

Pero ¿existe alguna diferencia específica en la educación de adultos? ¿Cuando la educación se realiza con personas adultas, se añade algo al concepto de educación que hemos establecido? La respuesta, ya lo hemos dicho antes, es interdisciplinar (incluye, pues, los puntos de vista de la Epistemología, la Antropología ética, la Sociología, la Psicología y la Pedagogía), pero en nuestro caso vamos a referirnos a las dos últimas perspectivas. Es decir, sin que con ello agotemos la reflexión sobre las señas de identidad de la educación de adultos, desde la visión psicopedagógica que adoptamos en este trabajo, creemos que buena parte del carácter específico de la educación de adultos depende de dos factores: por un lado, de lo que vayamos a entender por persona adulta (análisis psicológico) y, por otro, de los objetivos que definan este tipo de educación y del análisis del propio proceso educativo (reflexión pedagógica).

Lo podemos decir con más claridad: la diferencia añadida que representa la educación de adultos respecto al concepto de educación en general, dependerá también del significado que, desde el punto de vista psicológico y social, tenga el hecho de ser una persona adulta y, por otra parte, del modo en que se concrete el carácter optimizante de esta acción educativa. 
Más concretamente todavía: a partir de lo dicho hasta ahora sobre la Psicología de la edad adulta, ¿cabe pensar que el proceso educativo en el que participan las personas adultas debe ser diferente a otros procesos educativos? En segundo lugar, en relación con el carácter optimizante, ¿cuáles son los valores y los fines que han de presidir la acción educativa cuando ésta es protagonizada por personas adultas?

Estamos convencidos de que, si respondemos, aunque sea globalmente, a estas preguntas, habremos avanzado en la definición, si no de todas, al menos de algunas señas de identidad de la educación de adultos. Es evidente que no agotamos aquí el análisis sobre la especificidad de este sector educativo; sólo aspiramos a contribuir en esa dirección y, como decíamos en la introducción, esperamos otras aportaciones y debates sobre este asunto. Insistimos en que en este trabajo sólo pretendemos avanzar algunos apuntes sobre el tema, pero somos conscientes de que ni este método o sistema discursivo es el único ni las características sobre la educación de adultos que señalamos a continuación son las únicas.

\subsection{UNA EDUCACIÓN DE ADULTOS PARA TODOS, PERO DANDO PRIORIDAD A LOS MÁS NECESITADOS}

La primera de las señas de identidad tiene su base en la Psicología (está demostrado que todas las personas adultas son capaces y pueden aprender), aunque propiamente nace de la reflexión estrictamente pedagógica que se pregunta por los fines de la educación de adultos.

Durante mucho tiempo se ha pensado que la finalidad de la educación de adultos era meramente compensatoria y remedial. De la educación de adultos se decía que era una oferta educativa destinada a compensar el déficit de quienes fracasaron en la escuela o no tuvieron la oportunidad de asistir a ella. Era ésta una concepción de la educación de adultos que nos remite al concepto de resocialización, toda vez que con estas enseñanzas se buscaba resocializar a las personas adultas a las que se suponía marginadas.

Como se ve, estamos ante una concepción negativa de la educación de adultos (pensada para los que no...), que buscaba remediar este problema social. Pero, además de ser ésta una concepción negativa, también es una concepción restrictiva que limita la educación de adultos a unos determinados sujetos (los que poseen déficit en relación con el sistema educativo imperante) y a unas determinadas ofertas (aquellas precisamente encaminadas a suplir tales déficit: alfabetización, educación primaria, etc.).

Pero actualmente esta concepción se ha superado o, mejor, se está superando. Todo parece indicar que la tradicional perspectiva remedial y compensatoria no ha prosperado y actualmente, entre los profesionales y los par- 
ticipantes de la educación de adultos se comparte la idea de una educación de adultos para todos o, dicho de otra manera, se habla del derecho de todas las personas adultas a la educación, sea cual sea su nivel de formación previa y sean cuales sean sus metas formativas. De hecho, esta concepción global de la educación de adultos es la que ha mantenido la Unesco en las últimas conferencias internacionales dedicadas a este sector educativo. Así, en la Quinta Conferencia Internacional de Educación de Adultos celebrada en Hamburgo en 1997, se habla de la educación de adultos simplemente para todas las personas adultas y además se descarta el carácter compensatorio afirmando que se entiende por educación de adultos "el conjunto de procesos de aprendizaje, formal o no, gracias al cual las personas, a quien su entorno social considera adultas desarrollan sus capacidades, enriquecen sus conocimientos y mejoran sus competencias técnicas o profesionales, o las reorientan para atender a sus propias necesidades y a las de la sociedad" (Unesco, 1997a: 7).

No obstante, hay que hacer una precisión a lo dicho: si bien es verdad que todas las personas adultas tienen derecho a la educación, sigue teniendo vigencia que la educación de adultos tiene que dar prioridad a los sectores sociales más necesitados o, de lo contrario, la educación de adultos no estaría contribuyendo, como toda educación, a la igualdad entre los seres humanos. En el caso español, se trata de una finalidad compartida por no pocos autores (Requejo, 1994; Formariz, 1994; Jiménez y Sanz, 1995; Sanz, 1995, entre otros) que, además, se ha hecho presente en muchos textos legales de los últimos años.

En tal sentido, conviene no olvidar, como ya se decía en la Tercera Conferencia Internacional de Tokio sobre Educación de Adultos, que el incremento en las ofertas de formación de una comunidad tiende a favorecer, sobre todo, a los que menos lo necesitan, pues ya poseen un buen nivel de instrucción (Unesco, 1972: 21). Se trata en este caso de una de las debilidades y contradicciones más flagrantes de la educación de adultos: que los que más lo necesitan, los desfavorecidos social y económicamente, no se están beneficiando de los programas de formación dirigidos a los públicos adultos. Precisamente por ello, en la propia Conferencia de Tokio se planteaba esta pregunta: ¿cuál es pues la contribución de la educación de adultos a la resolución de los problemas sociales, a la reducción de las injusticias y a la eliminación de las desigualdades entre los hombres? En efecto, sobre todo en los países desarrollados, si no hacemos algo por corregir esta tendencia dando prioridad a los que más lo necesitan, no parece que estemos ajenos al peligro de que las ofertas de educación de adultos contribuyan a aumentar las diferencias sociales en lugar de a disminuirlas.

Por otra parte, hay que decir que la concepción de una educación de adultos para todos no sólo no se opone sino que resulta complementaria con la idea de priorizar a los sectores sociales más necesitados, porque, como dice Petrus (hablando del mismo problema en relación con la educación social), "sólo a partir de una concepción o perspectiva 'generalizante' será posible 
que la educación social [en nuestro caso, la educación de adultos] cambie determinadas realidades de la sociedad" (Petrus, 1997: 32).

Es decir, la educación de adultos se podrá convertir en un medio efectivo para reducir las desigualdades y compensar los desajustes sociales, si de hecho se convierte al mismo tiempo en un recurso para prevenir la marginación y actuar sobre las causas que generan los desajustes sociales. Para decirlo más claramente, si queremos que la educación de adultos se dedique especialmente a los que más lo necesitan, sólo podrá hacerlo efectivo si se sitúa en esta perspectiva generalizante (para todos) capaz de prevenir los problemas sociales y capaz de actuar sobre las causas de las desigualdades. Lo contrario acabaría cegando la propia dedicación a los más necesitados, al limitarla a remediar lo que la propia sociedad ha marginado.

Precisamente por ello, de acuerdo con las leyes vigentes en España, cualquier regulación de la educación básica (que es el tipo de educación que fundamentalmente necesitan los sectores sociales más desfavorecidos) debe considerarse como un derecho inalienable de los ciudadanos que, además, debe ser asegurado para las personas adultas y atendido de forma prioritaria por las administraciones públicas.

\subsection{UNA EDUCACIÓN DE ADULTOS COMUNITARIA}

Una de las expresiones con la que, durante muchos años, nos hemos referido a la educación de adultos es la extra-escolaridad, entendida como la actividad educativa que se desarrolla fuera del ámbito de la escuela. Lo mismo se ha venido diciendo de la educación social: que es un tipo de educación no escolar. Evidentemente, ésta es una definición que no nos agrada por excluyente y negativa (se dice lo que no es) además de ambigua e imprecisa, como sucede también con la educación social (Petrus, 1994: 177), pero hemos de admitir que resulta clarificadora cuando nos referimos a la práctica educativa y a su organización.

Queremos decir que, al hablar de extra-escolaridad, por oposición, ésta es una expresión que nos pone con contacto con el propio concepto de comunidad. Y aquí sí que reconocemos otra de las señas de identidad de la educación de adultos. En efecto, en el campo de la educación de adultos la comunidad se convierte en una de las características esenciales de este tipo de intervención educativa. Lo que decimos, entre otras razones, se fundamenta en el significado social que tiene la adultez, en las características de la personalidad de los adultos, en los roles sociales que se asumen en la edad adulta y en la importante presencia de acontecimientos sociales que tienen lugar en la vida de una persona una vez superada la adolescencia.

Esta perspectiva comunitaria con la que concebimos la educación de adultos es la que nos hace pensar que estamos ante un campo de la educa- 
ción cuya finalidad es, al mismo tiempo, el desarrollo individual y el desarrollo social; o mejor, nos referimos a una acción educativa donde el desarrollo personal (finalidad de toda educación) se considera inseparable de la optimización comunitaria. Está claro, pues, que no estamos exclusivamente ante ofertas educativas para el desarrollo del individuo, sino ante ofertas educativas en las que el desarrollo del individuo (la persona adulta desde el punto de vista psicológico se concibe como un ser eminentemente social) no se entiende sin su proyección social, sin la mejora de la comunidad, sin la solidaridad con los otros, sin la optimización del propio tejido social. Es decir, el significado social que posee la adultez es una de las razones, entre otras, que nos remiten a un significado también social de la educación de adultos.

Ésta es la razón por la que la educación de adultos se concibe como un factor de cambio social y, tal vez aquí, por el significado social que tiene la adultez, es donde encontramos con más claridad lo que la expresión de adultos añade al sustantivo educación. Está claro, pues, que nos referimos a las concepciones que se refieren a la educación de adultos como un medio para la mejora de la propia sociedad, pero conviene aclarar que no hablamos de los efectos sociales que indirectamente tiene toda acción educativa, sino de los cambios sociales que directamente genera la acción educativa cuando ésta es comunitaria. Concebida así, se entiende que la educación de adultos ha de intervenir directamente en el tejido social, sobre la propia realidad social que genera las situaciones de marginación, es decir, sobre sus causas.

Desde nuestro punto de vista, y de acuerdo con el propio concepto de educación del que partimos, consideramos que esta finalidad comunitaria constituye uno de los elementos esenciales del propio concepto de educación de adultos. La razón está, pensamos, en que al concretar esta finalidad se define la naturaleza y el horizonte utópico de la optimización (rasgo de toda acción educativa), pero aplicado a la educación de adultos.

Por todo ello, hemos de precisar que, cuando hablamos de una educación de adultos comunitaria, nos referimos a la comunidad como seña de identidad de la educación de adultos en un doble sentido:

a) La comunidad como fuente de educación. Se reconoce que no sólo educan la escuela o las instituciones formales convencionales; también educa la comunidad a través de múltiples medios y recursos (las empresas, las asociaciones, las instituciones, los medios de comunicación, etc.) y se entiende que la escuela o las instituciones educativas convencionales son un medio más, pero no los únicos.

b) La comunidad como destino de la educación. La comunidad no es sólo fuente o generadora de educación, también la comunidad se convierte en la dirección de la acción educativa, el norte o destino en el que convergen los esfuerzos de los educadores. Es decir, la comunidad se con- 
vierte en objeto de la acción educativa de unos educadores que centran su esfuerzo en educar no sólo a los individuos, sino también a la comunidad en general o a determinados grupos y colectivos.

Este doble sentido que damos al concepto de comunidad aplicado a la educación de adultos lo encontramos también en Petrus, aplicado a la educación social, cuando afirma que "la educación social es una acción que tiene a la comunidad como referente, se realiza en la comunidad y tiene en ella su principal elemento metodológico. Se trata pues de educar para la comunidad, en la comunidad, y con la comunidad (la cursiva es del propio autor). Al actuar así se reivindican nuevos espacios educativos, se crean nuevas sensibilidades y aparecen nuevas demandas de la mejora de esa sociedad" (Petrus, 1997: 32).

Por tanto, si bien el concepto de extra-escolaridad no nos habla de lo que es la educación de adultos, sino más bien de lo que no es; sin embargo, el concepto de comunidad sí nos aproxima al concepto y naturaleza de este tipo de educación. Esto tiene que ver con uno de los cambios más relevantes que se está produciendo en el campo de la educación de adultos: los profesionales de este sector educativo están abandonando el tradicional modelo escolar (extra-escolaridad); pero en este caso cuando se habla de modelo escolar no nos referimos exclusivamente a la escuela como ámbito de la educación, sino más bien al discurso pedagógico, a los métodos y, en general, a los supuestos teóricos que subyacen a las prácticas educativas que tradicionalmente se han aplicado con personas adultas. Al mismo tiempo, el abandono del modelo escolar está permitiendo la emergencia de un nuevo modelo de educación de adultos, un modelo denominado social (opuesto al escolar), entre otras razones, por la importancia que la comunidad tiene para la educación de las personas adultas.

\subsection{UNA EDUCACIÓN DE ADULTOS EN LA QUE LA PERSONA ADULTA ES SUJETO DE LA EDUCACIÓN}

Otro de los rasgos del perfil de la educación de adultos es que estamos ante un proceso educativo que realizan las personas adultas como sujetos. No hablamos, por tanto, de una actividad que se realiza sobre las personas adultas, sino de una actividad o un proceso que protagonizan y deciden las personas adultas, que actúan como sujetos de la educación, no como objetos de la educación (educandos) sobre los que se supone que operan otros sujetos (educadores).

Cuando hablamos de sujeto de la educación queremos darle a esta expresión todo el significado antropológico que ha tenido a lo largo de la Modernidad. Nos referimos a una idea de sujeto según la cual se admite que la racionalidad humana nos da acceso al conocimiento $y$, por tanto, podemos 
basar nuestras decisiones y nuestras acciones en algunas certezas, del mismo modo que se admite la existencia de criterios para valorar lo que sabemos y lo que debemos hacer; dicho de otro modo, esto es precisamente lo que equivale a afirmar que el ser humano es sujeto, un ser autónomo y racional, capaz de conocer y decidir su propio destino, lo contrario de ser un mero objeto, víctima de acontecimientos que están fuera de su control. Estamos convencidos de que la práctica de la educación de adultos no puede llevarse a cabo sin que se transmitan estos valores del sujeto y de la racionalidad en virtud de los cuales se entiende que la razón moderna es la que nos ha librado de la superstición, de la arbitrariedad, del capricho, del mito irracional, así como también la que nos puede librar de las calamidades y de la pobreza.

Se trata, en suma, de la idea de persona humana que posee un valor en sí misma, una persona dotada de racionalidad y autonomía, una persona concebida como un sujeto independiente que conoce y actúa con racionalidad y que, como tal, se aleja de las posiciones irracionales y dependientes propias de la época premoderna. Como dice Touraine (1993: 265), el logos divino de la época premoderna es sustituido por el Yo racional del sujeto moderno, capaz de entender las leyes inteligibles de la naturaleza. Ser sujeto es lo contrario de ser objeto, es lo contrario de la sumisión, de la dependencia; equivale a ser racional, autónomo, independiente, libre.

Desde el punto de vista de la teoría social, esta idea de sujeto la encontramos en otros autores, como Habermas y Giddens, por ejemplo. Entre los pedagogos, Freire es uno de los autores que se refieren al sujeto de la acción educativa como condición ineludible para que tenga lugar el aprendizaje crítico y emancipador. Según su concepción de la educación liberadora, el alumno es considerado sujeto, es decir, es autónomo, habla, posee una cultura, aprende. Por el contrario, para la educación bancaria, el alumno es objeto: no tiene autonomía, se limita a escuchar, es considerado inculto, es enseñado (Freire, 1992: 78).

Así pues, en el campo de la educación de adultos, el educando es sujeto (persona racional y autónoma) que decide educarse y para ello o bien lo hace sólo (hablaríamos de procesos de autoformación) o bien cuenta con alguna ayuda (hablaríamos de procesos de heteroformación), o también puede suceder que unas veces decida educarse solo, y otras, con ayuda; pero en todos los casos está claro que quien decide es la persona adulta. No cabe, pues, en este sentido, hablar de educación obligatoria, de sistemas de control, de disciplina, etc.

En efecto, la educación de adultos es un tipo de educación voluntaria, donde la motivación inicial está asegurada, dado que las personas adultas, si están participando en algún proceso de formación, será porque lo han decidido voluntariamente, sin coacción de ningún tipo, aunque entre las muchas motivaciones de los participantes existan las que nacen de necesidades instrumentales. 
Este énfasis que la educación de adultos pone en el sujeto racional y autónomo, capaz de aprender, de participar y de tomar decisiones se fundamenta en lo que ya hemos dicho acerca de la Psicología de la adultez: en la edad adulta se dan las condiciones madurativas suficientes para el ejercicio de la inteligencia (racionalidad) y de la autonomía (libertad), con la correspondiente independencia de criterio y de vida; lo que se ve reforzado por el hecho de que, desde el punto de vista psicosocial, la persona adulta se caracteriza por la responsabilidad en la toma de decisiones y en la acción.

Pero, al hablar de la identidad de la educación de adultos, no sólo destacamos la idea de sujeto basándonos en razones de carácter psicológico, también esta idea de sujeto conecta con una determinada tradición ética y filosófica que (con un optimismo crítico, que no ingenuo) cree firmemente en la capacidad de los seres humanos para pensar libremente y decidir su propio destino. En el fondo, esto no es otra cosa que reconocer que la educación es posible y sirve para que mejoren los seres humanos, base de lo que para Freire constituye la denominada Pedagogía de la esperanza. Ni la realidad ni el futuro son inexorables, nos dice el pedagogo brasileño, oponiéndose a los fatalistas y a los postmodernos que se declaran pesimistas e impotentes. "La educación, en verdad, necesita tanto de formación técnica, científica y profesional como de sueños y de utopía" (Freire, 1997: 34).

\subsection{UNA EDUCACIÓN DE ADULTOS BASADA EN LA AUTONOMÍA Y RESPONSABILIDAD DEL EDUCANDO}

La idea de sujeto racional y autónomo que decide formarse (motivación inicial) tiene que trasladarse al mismo proceso educativo (lo que afectaría a la motivación de mantenimiento). Esto significa que el desarrollo de la formación (el proceso de enseñanza-aprendizaje) no puede hacerse desde una perspectiva paidocéntrica, como si de niños frágiles, dependientes e inmaduros se tratara. De ser así estaríamos ante unas actividades educativas que se llevan a cabo ignorando que sus protagonistas son personas adultas capaces, autónomas y responsables.

En la práctica, si somos coherentes con lo dicho hasta ahora, se derivan dos consecuencias, estrechamente relacionadas entre sí, sobre las señas de identidad de la educación de adultos. Una, que en la educación de las personas adultas los educandos no sólo deciden formarse y lo hacen voluntariamente como sujetos (lo que comentábamos anteriormente), sino que deciden también sobre el propio proceso educativo y el modo de llevarse a cabo. En el fondo, estamos ante el derecho de las personas adultas a decidir, a tomar decisiones, sobre el tipo de formación que desean, los métodos a seguir, los roles a asumir en el proceso formativo, etc. 
La otra consecuencia práctica es que la responsabilidad del aprendizaje es del alumno, no del profesor, lo que supone un cambio de mentalidad consistente en sustituir la cultura de la enseñanza por la cultura del aprendizaje. El énfasis no hay que ponerlo tanto en lo que el profesor tiene que enseñar sino en lo que el alumno tiene que aprender. Dicho de otro modo: en la educación de adultos se enfatizan los procesos de autoaprendizaje sobre los procesos de heteroenseñanza, dando más importancia así a la necesaria responsabilidad con respecto a la propia formación que han de asumir los estudiantes.

Esto significa que hay que cambiar los roles tradicionales de profesor y de alumno y con ello los propios métodos educativos. El alumno adulto no espera, de forma pasiva, ser enseñado, se siente responsable de su aprendizaje y actúa en consecuencia, es decir, dirige su proceso de aprendizaje. Dado que desea aprender y se siente motivado para ello, las personas adultas se enfrentan a los procesos de formación con interés, con una actitud de búsqueda del conocimiento, aprovechando los diferentes medios y las oportunidades de aprendizaje. Debe quedar claro, no obstante, y esto ya lo decía Knowles (1982: 24), que el hecho de que los alumnos se sientan responsables de su formación y hablemos de procesos de autoaprendizaje no significa que los alumnos no sean enseñados; lo que cambia en este caso es la actitud del estudiante que admite ser enseñado, solo que de forma activa, como corresponde a quien se siente responsable de su aprendizaje. En esta misma idea insisten Brockett e Hiemstra (1993: 28) al poner de manifiesto la compatibilidad entre el individuo que asume la responsabilidad personal de su aprendizaje y la presencia de un profesor que orienta y fomenta el autoaprendizaje de los alumnos.

También tiene que cambiar el rol de profesor. Si la responsabilidad del proceso de aprendizaje descansa en el alumno, el profesor se convierte en un facilitador, un recurso, un consultor, un tutor, alguien que ayuda, que impulsa la participación, que aporta información, que provee recursos, que facilita contactos y promueve encuentros, un interlocutor válido para contrastar la información y los conocimientos. También el profesor colabora en el diagnóstico de necesidades, valora competencias y habilidades, facilita la evaluación del proceso de aprendizaje.

Pero en el caso del profesor, no sólo hemos de referirnos a cambios en su función. La educación de adultos que se basa en la autonomía y la responsabilidad del alumno exige también, por parte del profesor, el establecimiento de relaciones de igualdad y proximidad con los alumnos que resultan más coherentes con esta forma de concebir el proceso educativo.

En algunos casos, para facilitar esta nueva cultura basada en que el alumno asume la responsabilidad del aprendizaje, algunas instituciones dedicadas a la educación de personas adultas suelen contar con materiales didácticos específicamente diseñados para personas adultas. Suelen ser unos mate- 
riales didácticos que fundamentalmente cumplen la función de aportar la información relevante y necesaria sobre los diferentes temas. De este modo, se facilita que los alumnos estudien de forma autónoma y además que la actividad en las aulas no se limite exclusivamente a dar información, sino que se centre también en debates y actividades prácticas que profundizan los temas de estudio.

\subsection{UNA EDUCACIÓN DE ADULTOS COMO ESPACIO PARA LA PARTICIPACIÓN}

Hay otra cuestión importante que se va a convertir en un elemento complementario y, al mismo tiempo, reforzador de la cultura de la responsabilidad respecto de la propia formación: se trata de la participación de los alumnos. Si no hay participación real en el proceso educativo, no podemos hablar de asumir la propia responsabilidad en dicho proceso $y$, mucho menos, podemos hablar de sujeto, lo cual quiere decir que participación y responsabilidad operan como elementos indisociables.

No obstante, para que la participación sea posible se requieren determinadas condiciones. La primera afecta al propio profesor que tiene que relacionarse con los alumnos con actitudes claramente democráticas, tratando de fomentar en todo momento la comunicación abierta y sin trabas por parte de todos.

Pero además se requieren otras condiciones que afectan a las propias instituciones educativas. Es importante lo que decimos porque, desde el punto de vista metodológico y organizativo, si queremos fomentar la participación, tal vez sea necesario modificar la composición de los grupos, lo que, sin duda, va a afectar a la organización del centro y al horario del profesor y de los alumnos.

No obstante, participar es algo más que hablar en clase, decir la propia opinión, trabajar en grupo o darle la palabra a los alumnos. La clave de la participación está en la toma de decisiones. Si el alumno, como hemos dicho antes, es considerado sujeto y además, precisamente por su madurez y su nivel de desarrollo, admitimos que asume la responsabilidad respecto de su propio aprendizaje, si, por otra parte, reconocemos también que la participación es un valor educativo, está claro que los alumnos tienen que tomar decisiones, lo que significa que el proceso educativo tiene que ser negociado entre el estudiante y el profesor. Para decirlo más claramente: o los alumnos toman decisiones sobre su aprendizaje o, de lo contrario, no se les reconoce como personas adultas.

El problema es que, como reconocen Brockett e Hiemstra (1993: 46), para poder tomar decisiones es necesaria la existencia de opciones, $o$, de lo con- 
trario, la participación se quedará en la mera retórica. A partir de aquí parece estar claro que no tiene sentido, ni es coherente con la naturaleza de los educandos, plantear una formación de oferta para las personas adultas, sin opciones, como si de un paquete cerrado e independiente de los intereses de los usuarios se tratara. En el campo de la educación de adultos tenemos que hablar de una formación de demanda, basada en la existencia de opciones que permitirán la participación de los alumnos en la toma de decisiones.

Lo que sucede es que las opciones ni se plantean en abstracto ni se puede hablar de ellas en términos absolutos. En la práctica, la existencia o no de opciones siempre se va a referir a los tres componentes fundamentales de todos proceso educativo: la planificación, la realización y la evaluación de la acción formativa. En nuestro caso, hablar de una formación de demanda, basada en la existencia de opciones, no significa plantear la cuestión en términos de todo o nada, significa admitir grados en la toma de decisiones y que finalmente la planificación, la realización y la evaluación de las acciones formativas puedan ser el fruto de la negociación entre los profesores y los alumnos.

Como se ve, hemos hablado de la participación como una consecuencia educativa de la madurez psicológica de los educandos y como un factor clave para sentirse responsable de la propia formación Pero la participación también constituye un valor educativo en sí misma en una sociedad democrática. Y en tal sentido se comparte actualmente la idea de que la educación de adultos se convierta en un espacio de participación creíble y viable, un espacio, en suma, de radicalización de la democracia. Ayuste (1999: 233) se refiere en este sentido a los "centros de educación de adultos como contextos privilegiados para practicar la democracia participativa" y como espacios desde donde se "articulan la participación social y cultural de la comunidad". Pero esto no es posible sin esa idea de sujeto de la que hablábamos antes y sin una relación verdaderamente igualitaria entre profesores y alumnos. Habermas se refiere a ello cuando señala la necesidad de un diálogo igualitario en el que la validez del conocimiento y de las afirmaciones no dependan del poder que se ocupa sino de la capacidad de convencer que generan las propias ideas por sí mismas y sus fundamentos (Habermas, 1988).

\subsection{UNA EDUCACIÓN DE ADULTOS CRÍTICA Y EMANCIPADORA PARA LA SOCIEDAD DE LA INFORMACIONN}

Ya hemos dicho que la perspectiva eminentemente social de la adultez nos sitúa necesariamente ante una concepción también social de la educación de adultos. Pero ¿en qué sociedad vivimos y qué papel va a jugar en ella la educación? Es evidente que las señas de identidad de la educación de adultos no pueden definirse eludiendo el análisis social (que, además, en modo alguno 
puede ser aséptico o neutral) y las funciones de la educación en la sociedad en la que nos encontramos.

Se ha publicado un documento institucional que, entre otras cosas, aborda este asunto. Se trata de un informe encargado por la Unesco a una comisión internacional de expertos dirigidos por Delors (1996), que finalmente se ha editado con el título La educación encierra un tesoro. En el libro se reflexiona sobre la problemática de la educación del siglo XXI y se proponen recomendaciones y orientaciones de cara al futuro.

Los autores de esta obra ponen de manifiesto que la educación está siendo objeto actualmente de fuertes críticas y que, además, está siendo relegada a la última categoría de prioridades por razones económicas y financieras. No obstante, ante los problemas, desafíos e incertidumbres que sufren las sociedades actuales (desempleo, exclusión social, crecientes desigualdades sociales, deterioro del medio ambiente, etc.), se insiste en el documento en la necesidad ineludible de la educación: "Frente a los numerosos desafíos del porvenir, la educación constituye un instrumento indispensable para que la humanidad pueda progresar hacia los ideales de paz, libertad y justicia social... para hacer retroceder la pobreza, la exclusión, las incomprensiones, las opresiones, las guerras, etc." (Delors et al., 1996: 13).

Una de las claves de este documento de Delors tiene que ver con las relaciones que en la actualidad cabe establecer entre lo que se denomina la sociedad de la información, por una parte, y la necesidad de un sistema de educación amplio y permanente, por otra.

La expresión sociedad de la información es la que actualmente utilizan los sociólogos para denominar el tipo de sociedad en el que nos encontramos. Prácticamente todos los expertos en el tema coinciden en señalar que se ha superado el tipo de sociedad industrial y que actualmente nos encontramos en una sociedad esencialmente caracterizada por la información y el conocimiento, razón por la cual se la denomina sociedad de la información, o también sociedad cognitiva, o sociedad del conocimiento.

Así pues, cuando hablamos de la sociedad de la información nos referimos, según Castell, a las transformaciones estructurales (son cambios de fondo y de largo alcance, no coyunturales) que se están produciendo en las sociedades modernas por el efecto combinado de varios factores, entre los que destacan el impacto de la revolución tecnológica basada en la información/comunicación, la formación de una economía global y los cambios culturales, con especial incidencia en el rol de las mujeres y en el afloramiento de una conciencia ecológica (Castells, 1994: 15).

Entre otras cosas, esto significa que el poder y la propia estructura social no dependerán sólo de factores económicos o de la posesión de materias primas (como sucedía en la sociedad industrial), sino de los recursos de la 
mente humana para el uso de la información y de la comunicación. Con otras palabras, en la nueva sociedad de la información el poder y la estructura social estarán asociados al capital cultural (no al capital económico, propio de la sociedad industrial), tanto de los individuos como de las instituciones y empresas.

Esta es una de las ideas básicas que se explican en otra obra que se ocupa también de este problema, el Libro Blanco sobre la educación y la formación. Según este libro (editado por la Comisión Europea con el título Enseñar y aprender. Hacia la sociedad del conocimiento), se constata que la posición de cada individuo en la sociedad depende cada vez más de las competencias y de los conocimientos que haya sabido adquirir a lo largo de su formación: "la educación y la formación serán, más que nunca, los principales vectores de identificación, pertenencia y promoción social" (...) "Cada vez más, las capacidades para aprender y la posesión de conocimientos fundamentales colocarán a los individuos en relación con los demás individuos en las relaciones sociales. La posición de cada uno en el espacio del saber y de la competencia será decisiva. Dicha posición relativa, que podemos calificar de 'relación cognitiva' estructurará cada vez más nuestras sociedades" (Comisión Europea, 1996: 16 y 17).

Asimismo, esta posición central que está ocupando el conocimiento produce efectos paradójicos en la actual sociedad de la información: por un lado, aumentan las posibilidades de acceso a la información y con ello las oportunidades y las posibilidades de igualdad para todos; pero, al mismo tiempo, los constantes cambios sociales, las transformaciones laborales y la necesidad de renovar las competencias adquiridas, han aumentado las incertidumbres y están creando situaciones de exclusión intolerables (Comisión Europea, 1996: 5).

Ello es debido a que la importancia que tiene el capital cultural en la sociedad de la información hace que las desigualdades sociales no sólo dependan de factores económicos, sino de la formación recibida y de la capacidad para seguir aprendiendo a lo largo de toda la vida. Los peligros y las amenazas que supone esta situación son claros para Delors y sus colaboradores: "El principal peligro es que se abra un abismo entre una minoría capaz de moverse en ese mundo nuevo en formación y una mayoría que se siente sacudida por los acontecimientos e impotente para influir en el destino colectivo, con los riesgos de un retroceso democrático y de rebeliones múltiples" (Delors, 1996: 54).

No son pocos los autores que se refieren a las desigualdades que se están generando en la sociedad de la información. Según Flecha, vivimos en una sociedad en la que están surgiendo nuevas desigualdades educativas debido a que los nuevos saberes que demanda la sociedad de la información se distribuyen de forma desigual en función del nivel de estudios, del grupo social, del género o de la edad (Flecha, 1994: 61). 
Para Majó, estamos ante una nueva sociedad que comporta tres principales riesgos con relación al acceso y al uso de la información: el riesgo de los que quedan excluidos por falta de acceso físico a las redes por razones geográficas o económicas; el riesgo de ser excluidos por problemas de competencia laboral o por la dificultad de seguir aprendiendo; finalmente, el riesgo de exclusión debido a la incapacidad de convertir la información en conocimiento (Majó, 1996 y 1997).

Se trata, en suma, de una sociedad en la que el individuo se verá cada vez más enfrentado a situaciones diversas y complejas que evolucionan de manera imprevisible en medio de un flujo creciente de información. Según la Comisión Europea, el riesgo de división social es evidente: "existe un riesgo de división entre los que pueden interpretar esta información, los que sólo pueden utilizarla y los que no pueden interpretarla ni utilizarla. En otros términos, entre los que saben y los que no saben" (Comisión Europea (1996: 7).

Ante este riesgo evidente que está suponiendo la actual sociedad de la información, ¿qué función cabe esperar de la educación de adultos? Desde nuestro punto de vista (y vemos aquí otra de las señas de identidad de este campo de la educación), sólo un tipo de educación de adultos crítica y emancipatoria puede hacer frente a esta situación. Esta visión de la educación es la que en la literatura pedagógica se denomina Pedagogía Crítica, una concepción estrechamente vinculada al aprendizaje dialógico o a la pedagogía liberadora de Freire (1992: 75-99), la misma concepción global a la que se refiere Mezirow (1994: 181-187) cuando habla de la teoría crítica de la educación de adultos o de aprendizaje autorreflexivo.

Sin que pretendamos explicar aquí exhaustivamente todo lo que esto quiere decir (otros autores ya lo hacen ampliamente, por ejemplo, Pérez Gómez, 1998), conviene que al menos señalemos dos aspectos que nos parecen importantes con relación al papel de la educación de adultos en la sociedad de la información: la necesidad de convertir la información en conocimiento y la idea de red educativa.

El primer aspecto que nos gustaría destacar con relación a la concepción crítica y emancipadora de la educación de adultos es el que trata de responder a uno de los problemas de la sociedad de la información, cuál es la dificultad de convertir la información en conocimiento. Por lo que sabemos, todo parece indicar que la racionalidad, basada en el lenguaje y en el diálogo, precisa ser optimizada mediante la educación, lo que al mismo tiempo incrementará nuestra libertad y la propia capacidad racional. Algunos autores incluso llegan a afirmar que realmente educar es potenciar la razón (Savater, 1998) o que la educación es una mediación entre sistemas inteligentes (Martínez, 1986). Lo que queremos decir es que la educación de adultos tiene que educar en el pensamiento racional, en la racionalidad crítica, tiene que hacer que la información se convierta en conocimiento mediante la reflexión, el diálogo y el debate; la información no se aporta sin más, hay 
que relacionarla, contextualizarla, interpretarla, valorarla, contrastarla, criticarla. Por este camino estamos convencidos de que la educación de adultos conseguirá ser crítica y emancipadora y promoverá unos ciudadanos racionales, autónomos, capaces de aprender y de mejorar las condiciones de vida. Se trata, en suma, de que la educación funcione como si de una carta de navegación se tratara, para que cada individuo pueda orientarse y encontrar su propio norte en medio de este mundo complejo y no menos confuso: "En cierto sentido, la educación se ve obligada a proporcionar las cartas náuticas de un mundo complejo y en perpetua agitación y, al mismo tiempo, la brújula para poder navegar por él" (Delors et al., 1996: 95).

En segundo lugar, desde el punto de vista legal y organizativo, la respuesta educativa ante la sociedad de la información nos conecta con la idea de red educativa. Ello lo que quiere decir es que las leyes encaminadas a regular la educación de adultos en la sociedad de la información no pueden concebir este campo de la educación como un servicio exclusivo de enseñanza, sino como un conjunto de redès educativas existentes en la comunidad al servicio de las políticas sociales y de los programas globales de desarrollo. En la práctica, esto equivale a legislar sobre la educación de adultos desde una perspectiva comunitaria, admitiendo que en la comunidad existe una diversidad de instituciones que operan en el campo de la educación (empresas, centros educativos, instituciones públicas, medios de comunicación, etc.) y una diversidad de ofertas que invitan a los sujetos a elegir libremente dónde y cuándo estudiar, qué estudiar y cómo, etc.

Al mismo tiempo, esta idea de red educativa da más importancia al aprendizaje que a la enseñanza (aprendizaje versus enseñanza). Significa que estamos ante un tipo de educación que valora no tanto el recorrido escolar del alumno, como los aprendizajes obtenidos independientemente de la forma de obtenerlos; desde el punto de vista de la clasificación del universo educativo que hacen los pedagogos, de lo dicho se deriva que los efectos educativos a los que se refiere la educación de adultos pueden tener su origen en las enseñanzas formales, en las enseñanzas no formales, e incluso ser fruto de la experiencia o de actividades educativas informales.

No obstante, para que, a nivel comunitario, sea viable esta estructura educativa reticular, será necesario que la legislación sobre educación de adultos facilite el establecimiento de relaciones funcionales en el universo educativo mediante mecanismos de coordinación, planificación y gestión.

\subsection{EDUCACIÓN DE ADULTOS Y ENSEÑANZAS OFICIALES}

Hasta ahora hemos hablado de la educación de adultos en general. Lo que hasta aquí hemos definido como algunas señas de identidad de la edu- 
cación de adultos es aplicable, en términos generales, a cualquier proceso educativo en el que participen las personas adultas consideradas como tales en la sociedad. En suma, desde nuestro punto de vista, creemos que la concepción de la educación de adultos que hemos explicitado es aplicable a los procesos de formación laboral en el seno de las empresas, a las acciones formativas de carácter ocupacional, a toda la gama de cursos de carácter cultural para las personas adultas, a los programas de desarrollo comunitario, a las ofertas de formación y de animación para mayores, etc. y también, cómo no, a las enseñanzas oficiales específicamente dirigidas a las personas adultas.

Con todo, en este último caso, cuando se trata de la educación de adultos que conduce a las titulaciones oficiales, creemos que la reflexión sobre las señas de identidad merece una especial atención por dos razones fundamentales: una, por la importancia que tienen las ofertas oficiales para la reducción de las desigualdades o para atender a los sectores de población más necesitados; dos, por la influencia que este tipo de ofertas, sus metodologías y sus propios profesionales suelen ejercer en la educación de adultos en general.

Debe quedar claro que, al hablar de enseñanzas oficiales para personas adultas, nos referimos a las enseñanzas denominadas formales, que remiten a alguna titulación oficial regulada por las autoridades educativas: enseñanzas que conducen al título de Graduado en Educación Secundaria, enseñanzas de Bachillerato, enseñanzas de Formación Profesional, etc.

Lo primero que hay que señalar en relación a estas enseñanzas oficiales para personas adultas es el cambio en relación con el currículo que se ha llevado a cabo en la última regulación legal de estas enseñanzas, a partir de la publicación en 1990 de la Ley Orgánica de Ordenación del Sistema Educativo (la LOGSE). Según esta nueva ley, por primera vez en nuestro país existe la base legal suficiente para que las enseñanzas formales dirigidas a las personas adultas cuenten con un currículo adaptado y/o específico para este tipo de públicos. Así, en los artículo 52.1 y 53.2 de la LOGSE se ordena que, cuando las enseñanzas de formación básica, de bachillerato o de formación profesional se dirijan a las personas adultas, tales currículos han de ser adaptados o han de contar con una oferta educativa específica y con una organización propia.

En segundo lugar, hay otro aspecto destacable (sobre el que ya hemos hablado en el apartado anterior 2.4.) referido a la organización y la metodología de la educación de personas adultas. En tal sentido, la LOGSE sólo señala un principio, el autoaprendizaje, y lo expresa en los siguientes términos: "La organización y la metodología de la educación de adultos se basarán en el autoaprendizaje, en función de sus experiencias, necesidades e intereses, a través de la enseñanza presencial y, por sus adecuadas características, de la educación a distancia" (art. 51.5). En este caso, el autoaprendizaje 
no sólo constituye una de las señas de identidad de la educación de adultos en general, sino que además representa un mandato legal de las autoridades educativas a la hora de diseñar y desarrollar las enseñanzas que conducen a las titulaciones oficiales.

Desde nuestro punto de vista, está claro que a las razones psicopedagógicas acerca de las señas de identidad de la educación de adultos se añaden ahora nuevas razones de carácter legal que inciden en la misma dirección del carácter específico de la educación de las personas adultas. Lo dicho tiene dos consecuencias para la práctica muy importantes. Una es que los currículos de las enseñanzas formales para personas adultas no pueden ser los mismos que los diseños curriculares de las enseñanzas escolares dirigidas a los niños y adolescentes, sino que han de ser unos currículos propios que den respuestas educativas a las necesidades (instrumentales, personales, familiares, laborales, sociales, económicas, políticas, etc.) que tienen las personas adultas y sus comunidades.

En segundo lugar, el diseño de tales currículos tiene que ser lo suficientemente abierto para dar lugar a la participación (y negociación) de las personas adultas en su definición. De este modo, podemos hablar también de una enseñanza formal que tiene en cuenta la demanda y que finalmente se contextualiza. Lo contrario sería algo así como tratar a las personas adultas como niños.

Por otra parte, por tratarse de las enseñanzas formales para personas adultas, hay otra cuestión que merece ser comentada y que afecta también a las señas de identidad de las ofertas educativas para adultos que conducen a los títulos oficiales. Se trata de la experiencia de las personas adultas y del modo en que afecta a las enseñanzas oficiales. Está claro que en este caso nos encontramos con una realidad significativamente diferente según se trate de niños y adolescentes o de adultos. Éstos, a diferencia de aquéllos, han adquirido una experiencia a lo largo de su vida, experiencia que sin duda ha podido tener efectos optimizantes desde el punto de vista educativo. La pregunta es: ¿esta experiencia ha logrado consolidar algunos aprendizajes que aparecen en términos de objetivos y competencias en los currículos de las enseñanzas que conducen a las titulaciones oficiales?

Desde una perspectiva psicopedagógica, la respuesta es que sí, en general, aunque en cada caso deba ser una cuestión que los profesionales de la educación han de comprobar. Lo que está claro es que, cada vez más, nos encontramos con personas adultas que no tienen, por ejemplo, el nuevo título de Graduado en Educación Secundaria, pero sin embargo, han trabajado como limpiadoras en Londres y saben inglés, o han leído mucho y redactan con cierta soltura, o por su trabajo han tenido que enfrentarse a diferentes problemas de matemáticas o contabilidad. ¿A estas personas adultas, si aspiran a tener un título oficial, hay que volverles a enseñar lo que ya saben? Semejante despropósito, además de irracional, significaría una pérdida de 
tiempo para las personas adultas y, sobre todo, una negación de su dignidad intolerable.

Por esta razón, en relación con las enseñanzas para adultos que conducen a las titulaciones oficiales hemos de señalar otro de los rasgos específicos de la educación de adultos. El currículo de estas enseñanzas que finalmente se publique en el boletín oficial debe reunir dos requisitos: por un lado, han de suprimirse las exigencias formales y administrativas relativas al nivel de instrucción previamente adquirido, subordinando exclusivamente la participación en un programa de formación a la capacidad y conocimientos previos de las personas adultas para seguir la formación impartida; y por otra parte, el currículo tiene que incorporar sistemas flexibles de acreditación que permitan reconocer, en términos de educación formal, aquellos objetivos y competencias que vienen definidos en los currículos oficiales y que las personas adultas han podido adquirir al margen de las enseñanzas convencionales, debido a la experiencia o debido a otras enseñanzas de carácter no formal. Ello significa fortalecer los vínculos y pasarelas entre enseñanza formal y enseñanza no formal e informal, admitiendo que lo importante no es tanto el camino que ha seguido el sujeto, sino lo que ha adquirido y aprendido, tal como se solicita desde instancias internacionales, como la Unesco (1985: 47, 48 y 54); 1997a: artículo 10; 1997b: artículos 19, 21 y 31), la Comisión Europea (1996: 8 y 39) y el texto de Delors (1996: $158,121,143,158,160)$.

Por otra parte, este asunto tiene que ver con las consecuencias que suelen tener las reformas educativas al elevar el nivel de formación básica, una cuestión ampliamente estudiada por Flecha (teoría de la desnivelación) y por Alonso Maturana (fenómeno de la obsolescencia académica). Se trata de algo que ya sucedió con la Ley General de Educación (LGE) de 1970 y que ha vuelto a suceder de nuevo con la Ley de Ordenación General del Sistema Educativo (LOGSE) de 1990: al recualificar al alza el nuevo título de formación básica (el Graduado Escolar, según la LGE, y el Graduado en Educación Secundaria, según la LOGSE) se termina por recualificar a la baja el título anterior (Flecha, 1990b: 106; Alonso Maturana, 1997: 149). El único modo de evitar estos efectos no deseados (aunque no por ello menos dramáticos) de las reformas educativas es que, en relación con estas enseñanzas para adultos, tales reformas incorporen medidas destinadas a mantener el reconocimiento social de las competencias básicas que ya poseen las personas adultas.

En el fondo, lo dicho hasta ahora sobre el carácter propio de aquellas ofertas educativas para adultos que conducen a titulaciones oficiales plantea la necesidad de que la educación de adultos se contemple como un sistema propio (subsistema) que exige una regulación legislativa diferente al sistema educativo ordinario y escolar para niños y adolescentes; ello, por supuesto, sin perjuicio de que la propia legislación establezca las relaciones entre este subsistema de educación y el formal-escolar. 


\section{PEDAGOGÍA SOCIAL Y EDUCACIÓN DE ADULTOS. A MODO DE CONCLUSIÓN}

Llegados hasta aquí, una vez que hemos planteado lo que desde nuestro punto de vista son las señas de identidad de la educación de adultos y algunos de sus fundamentos, es obligado retomar las cuestiones que planteába-

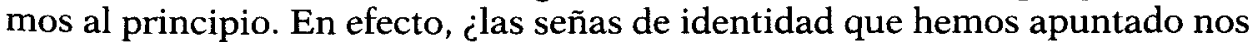
autorizan a afirmar que, en el caso de la educación de adultos, estamos ante una especie educativa nueva? También podemos formular esta cuestión de otra manera: ¿podemos hablar con propiedad de una Pedagogía específica para las personas adultas?

Tiene importancia esta pregunta, sobre todo por las consecuencias prácticas que tiene. De todos es sabido que en el pasado ha existido una Pedagogía dominante que veía la educación y el fenómeno educativo desde dos variables fundamentales: la niñez y la adolescencia, por un lado, y la escuela, por otro. Este inexorable imperio pedagógico tradicionalmente ha ignorado la edad adulta como una etapa apta para la educación y, además, ha hecho caso omiso de las posibilidades educativas de la comunidad. Los efectos ejercidos por este discurso dominante en la educación de adultos ya son conocidos por todos: por este camino se ha instalado lo que se conoce como el modelo escolar de educación de adultos. Es éste un modelo según el cual las prácticas educativas que se realizan con personas adultas ven en la escuela para niños y adolescentes su mejor ejemplo, su modelo de actuación. Cuando existía un problema educativo en el campo de la educación de adultos lo que se hacía era mirar a la escuela a ver cómo se abordaba; así la escuela y el discurso escolar durante muchos años se ha convertido en fuente de inspiración y única referencia para la educación de las personas adultas.

Uno de los efectos más perjudiciales para la educación de adultos del modelo escolar lo hemos podido comprobar en algunas legislaciones. En no pocos casos, cuando los gobiernos han legislado sobre la formación de personas adultas lo han hecho en clave escolar, es decir, desde el mimetismo de la legislación existente para las escuelas y centros de enseñanza media, reproduciendo así las mismas normas que para niños y adolescentes. Es decir, en la mayoría de los casos se ha legislado desde la Pedagogía tradicional dominante. Todo parece indicar que las administraciones educativas de antemano ya habían respondido a la pregunta anterior negando la existencia de una Pedagogía propia para las personas adultas y, con ello, el desarrollo de una especie educativa nueva. Con todo, merece la pena que entremos en el fondo de la cuestión.

En primer lugar, hay que señalar un hecho que se viene consolidando en los últimos años: la emergencia de un nuevo modelo de actuación educativa que se está implantando en el campo de la educación de adultos, un nuevo modelo social que está consiguiendo sustituir al tradicional modelo escolar, 
fruto este último del discurso pedagógico que ha tenido a la escuela y a las jóvenes generaciones como única referencia durante muchos años.

Cuando en el apartado anterior hemos hablado de las señas de identidad de la educación de adultos, en el fondo, lo que hemos hecho no es otra cosa que señalar algunas características de lo que entendemos por ese modelo social de educación de adultos. En efecto, para el modelo social se habla de una educación de adultos para todos y no sólo para cubrir los déficit educativos y sociales, pero en este caso el carácter social se acentúa todavía más cuando se afirma que sólo en el marco más amplio de una educación de adultos generalizante (como derecho de todos a la educación) cobra verdadero sentido el que se dé prioridad a los sectores sociales más necesitados. Ésta es una de las razones, entre otras, por las que la educación de adultos se caracteriza por ser un tipo de educación comunitaria donde la comunidad, y no sólo la escuela, se convierte en el espacio más amplio en el que tiene lugar la educación, y donde también la comunidad, además de los individuos, se convierte en sujeto de la acción educativa por parte de los profesionales que trabajan en este campo de la educación.

También la idea de sujeto (capaz de conocer, de aprender y de cambiar) es otra de las señas de identidad que se asocia al modelo social de educación de adultos, sobre todo, por oposición al modelo escolar que concibe al educando como el objeto de la educación sobre el que se suponía que se depositaba el conocimiento y el aprendizaje. Nos referimos a un sujeto de la educación autónomo, que, como tal persona adulta, decide aprender libremente y asume la responsabilidad de su proceso de aprendizaje; para el modelo escolar, sin embargo, que es un modelo obligatorio, la responsabilidad principal no descansa en el educando sino en el educador. Precisamente por ello se afirma que estamos ante un modelo de educación de adultos participado, negociado, basado en la demanda, no impuesto, ni cerrado; se trata, en suma, de un modelo en el que la toma de decisiones por parte de los educandos (sujetos adultos) en un espacio de diálogo (participación democrática) constituye otra de las claves del modelo social de educación de adultos del que estamos hablando.

Otra característica de este modelo social es el que se refiere a la función de la educación de adultos en la actual sociedad de la información. En este sentido, al modelo social de educación de adultos se le reconoce una función de educación permanente, crítica y emancipadora, que capacite a las personas adultas para convertir la información en conocimiento y las posibilidades de cambio en una esperanza creíble. No se ha entendido así, sin embargo, el modelo escolar, más propio de la sociedad industrial, que tendía a enfatizar los procesos de formación inicial, con un enfoque más reproductivo del aprendizaje.

Pero en todo este proceso, la verdadera asignatura pendiente en la implantación de un modelo social de educación de adultos está en las ense- 
ñanzas para personas adultas que conducen a las titulaciones oficiales del sistema educativo formal. En este caso, el carácter específico de la educación de adultos obliga a que este sector educativo sea considerado como un sistema que precisa de una legislación diferente a la que ya existe para el modelo escolar de los niños y adolescentes. No creemos que la solución para la educación de adultos sea mejorar el modelo escolar. Todo lo contrario, lo que la educación de adultos necesita es alejarse del modelo escolar y consolidar sus propias señas de identidad como un modelo específico, lo que, en consecuencia, exige también un tratamiento legal diferenciado, como un subsistema educativo con entidad propia, aunque integrado en un proyecto global de educación permanente, tal como señala la Unesco (1981: 83).

Así pues, cuando hablamos del carácter específico de la educación de adultos nos referimos a la oposición que existe entre las señas de identidad del modelo social y las características del modelo escolar. Conviene aclarar, con todo, que si comparamos las señas de identidad del modelo social con las del modelo escolar, lo que se advierte en la mayoría de los casos es una oposición real (de naturaleza) y en otros una diferencia de énfasis (de grado); pero en conjunto, creemos que lo que se percibe entre ambos modelos es una oposición global, como si de dos teorías educativas y opuestas se tratase.

Teniendo en cuenta los planteamientos de Moore (1987) acerca de la estructura, supuestos y componentes de las teorías educativas, estamos convencidos de que el modelo social de educación de adultos constituye una teoría educativa específica o una especie educativa nueva precisamente porque se trata de una práctica educativa desde la que se responde de manera diferencial y propia a las variables fundamentales que subyacen a todo proceso educativo y que podríamos formular como sigue: ¿para qué se educa? (finalidades), ¿quiénes son los protagonistas? (educandos y educadores), y finalmente, ¿qué enseñar-aprender y cómo? (currículo y organización). Pero insistimos en que la diferencia con que se responde a estas cuestiones, según se trate del modelo social o del modelo escolar, no es una mera diferencia de énfasis o de grado, sino más bien una diferencia global y de naturaleza.

Así pues, podemos afirmar con propiedad que, cuando hablamos de la educación de adultos, estamos ante una teoría educativa específica, una especie educativa nueva, cuyas características son las propias de un tipo de educación social, razón por la cual tiene sentido que destaquemos lo que consideramos un discurso social de la educación de adultos, un modelo social de educación, cuyo marco teórico más amplio no puede ser otro que el de la Pedagogía Social. Es en este marco más amplio, y no en el de la Pedagogía Escolar, donde creemos que la educación de adultos encontrará un discurso de referencia fértil y ambicioso y desde donde este sector educativo se podrá desarrollar como una práctica educativa diferencial y como un saber propio.

Queremos terminar como hemos comenzado, con una breve alusión a Marín Ibáñez; sirvan para ello las palabras que pronunció en relación con el 
tema que nos ocupa, y especialmente para reforzar lo que hemos dicho sobre el cambio en el papel del profesorado que se necesita en la educación de las personas adultas: "Naturalmente el papel del profesor cambia también en este tipo de enseñanza. Ya no es quien posee todo el saber, que imparte a un pasivo alumno y cuya fiel reproducción exige el día del examen. Ahora es el calificado colaborador del aprendizaje, ayuda al alumno a diseñar la marcha del trabajo, le facilita estímulos, ofrece materiales, prepara las experiencias más adecuadas y contribuye a clarificar los objetivos. Participa en todos los momentos del aprendizaje, mas no los impone al discente, según los usos tradicionales" (1977: 107).

En el legado intelectual de Marín Ibáñez (1977: 115), la concepción de la función del profesorado en el campo de la educación permanente va más allá de un mero cambio metodológico y técnico para proyectarse en un verdadero compromiso con el cambio social.

Se requiere un profesorado bien preparado que no sólo transmita saberes, sino que ayude a contemplar y a operar sobre la realidad, a resolver sus problemas, a proyectarse cara al futuro, a anticiparse a las dificultades, a conocer la habilidad de enfrentarse con los nuevos desafíos, a ser capaces de recoger información de todas las fuentes y a tomar decisiones válidas en todas las situaciones posibles. Una Pedagogía, en definitiva, que sea transformadora de la realidad, prospectiva y futurizante, más que repetidora de viejos patrones de conducta o mera transmisora de valores cuidadosamente acumulados a lo largo de toda la historia.

\section{BIBLIOGRAFÍA}

ALONSO MATURANA, R. y OTROS (1997). Nuevo contrato educativo: cambio social y cambio institucional. En García Carrasco, J. (coord.), Educación de adultos. Barcelona: Ariel.

AYUSTE, A. (1999). Participación, acción comunicativa y educación de personas adultas (Tesis doctoral). Barcelona: Universidad de Barcelona.

BALTES, P. B. (1991). Psicología Evolutiva del ciclo vital. Algunas observaciones convergentes sobre historia y teoría. En Marchesi, A., Carretero, M., Palacios, J., Psicología Evolutiva 1: Teorías y métodos. Madrid: Alianza.

BLANCO ABARCA, A. (1991). Factores psicosociales de la vida adulta. En Carretero, M., Palacios, J., Marchesi, A., Psicología evolutiva 3. Adoles- cencia, madurez y senectud. Madrid: Alianza.

BOND, C. \& WILSON, V. (1998). Experiential learning: fron theory to practice. En Lifelong Learning in Europe, KVS Fundation, Finland, 3; 139-147.

BROCKETT, R, G. y HIEMSTRA, R. (1993). El aprendizaje autodirigido en la educación de adultos. Barcelona: Paidós.

CASTELLS, M. (1994). Flujos, redes e identidades: una teoría crítica de la sociedad informacional. En Castells, M., Flecha, R. y otros, Nuevas perspectivas críticas en educación. Barcelona: Paidós.

CECI, S. J. y LIKER J. (1986). Academic and nonacademic intelligence: an experimental separation. En Stern- 
berg, R. J. y Wagner, R. K. (Edit.), Practical Intelligence. Nature and origins of competence in the everyday world. London: Cambribge University Press.

CLEMENTE, A. (1995). Psicología del desarrollo adulto. Madrid: Narcea.

COLE, M. y SCRIBNER, S. (1989). Introducción. En Vygotsky. El desarrollo de los procesos psicológicos superiores. Barcelona: Crítica.

COMISIÓN EUROPEA (1996). Enseñary aprender. Hacia la sociedad del conocimiento. Libro Blanco sobre la educación y la formación. Luxemburgo: Oficina de Publicaciones Oficiales de las Comunidades Europeas.

CORRAL, A. (1992). El desarrollo intelectual durante la vida adulta y la vejez. En García Madruga, J. A. y Lacasa, P., Psicología evolutiva 2. Madrid: Universidad Nacional de Educación a Distancia.

CRAIG, G. J. (1997). Desarrollo Psicológico. México: Prentice-Hall Hispanoamericana.

DELORS, J. y OTROS (1996). La educación encierra un tesoro. Madrid: Santillana-UNESCO.

ERIKSON, E. (1981). La adultez. México: Fondo de Cultura Económica.

FERRÁNDEZ, A., GAIRÍN, J. y TEJADA, J. (1990). El proceso de aprendizaje en el adulto. Madrid: Diagrama.

FLECHA, R. (1990a). Educación de personas adultas. Propuestas para los años noventa. Barcelona: El Roure.

FLECHA, R. (1990b). Nueva desigualdad cultural. Barcelona: El Roure.

FLECHA, R. (1994). Las nuevas desigualdades educativas. En Castells, M., Flecha, R. y otros, Nuevas perspectivas criticas en educación. Barcelona: Paidós.

FLECHA, R. (1997). Compartiendo palabras. El aprendizaje de las personas adultas a través del diálogo. Barcelona: Paidós.

FORMARIZ, A. (1994). Política autonómica de educación de adultos: Cataluña. En Requejo (Coord.), Poli- tica de educación de adultos. Santiago: Tórculo.

FREIRE, P. (1992). Pedagogía del oprimido. Madrid: Siglo XXI.

FREIRE, P. (1997). A la sombra de este árbol. Barcelona: El Roure.

GARCIA GARCÍA, L. A. y OTROS (1998a). Perfiles psicoeducativos en la educación para personas adultas de Canarias. En Evaluación e Intervención Psicoeducativa. Revista Interuniversitaria de Psicología de la Educación, 1, 119-139.

GARCÍA GARCÍA, L. A. y OTROS (1998b). Enseñanza de adultos: motivos de abandono del sistema educativo. En Evaluación e Intervención Psicoeducativa. Revista Interuniversitaria de Psicología de la Educación, 1, 141-150.

GARCIA MADRUGA, J. A. y CARRETERO, M. (1991). La inteligencia en la vida adulta. En Carretero, $\mathbf{M}$., Palacios, J., Marchesi, A., Psicología evolutiva 3. Adolescencia, madurez $y$ senectud. Madrid: Alianza.

HABERMAS, J. (1988). Teoría de la acción comunicativa. Madrid: Taurus.

HAVIGHURST, R. J. (1953). Human development and education. New York: Longman. En Craig, op. cit.

HELSON, R. y WINK, P. (1992). Personality change in women from the early 40 s to the 50s. Psychology and Aging, 7, 45-56.

HORN, J. L. y CATTELL, R. B. (1967). Age diferences in fluid and crystallized intelligence. Acta Psychologica, 26, 107-129.

INE (1998). Encuesta de Población activa. Resultados detallados. Primer trimestre de 1998. Madrid: Instituto Nacional de Estadística.

JIMÉNEZ, R y SANZ, F. (1995). Psicosociología de los destinatarios de la educación de personas adultas. En Sanz (Dir.), La formación en educación de personas adultas (Tomo 1). Madrid: UNED.

KNOWLES, M. S. (1968). Andragogy, not pedagogy! Adult Leadership, 16, 50-352, 386. 
KNOWLES, M. S. (1982). El estudio autodirigido. México: Alhambra Mexicana.

LEHR, U. (1979). Psicología de la senectud. Barcelona: Herder.

LEÓN CASCÓN, J. A Y CARRETERO, M. (1992). Perspectivas en el estudio del desarrollo cognitivo durante la vida adulta. En García Madruga, J. A. y Lacasa, P., Psicología evolutiva 2. Madrid: Universidad Nacional de Educación a Distancia.

LEON, A. (1986). Aspectos psicológicos de la educación permanente. En Debesse, M y Mialaret, G., Formación continua y educación permanente. Barcelona: Oikos-tau.

LEVINSON, D. J. (1978). The seasons of a man's life. New York: Knopf.

MAJÓ, J. (1996). Educación a lo largo de la vida en la sociedad de la información. En Diálogos. Educación y formación de personas adultas, núm. 6-7, 45-47.

MAJO, J. (1997). Chips, cables y poder. Barcelona: Planeta.

MARÍN IBÁÑEZ, R. (1977). La educación continuada, una nueva frontera educativa. En La enseñanza a distancia y los medidos de telecomunicación. Madrid: Fundación para el desarrollo de la función social de las comunicaciones (FUNDESCO, núm. 23, pp. 67119).

MARTÍN GARCÍA, V. (1994). Educación $y$ envejecimiento. Barcelona: PPU.

MARTÍNEZ, M. (1986). Inteligencia y educación. Barcelona: PPU.

MASSOT, M. (1996). El aprendizaje en autonomía en los centros de educación permanente de adultos. Revista de Educación a Distancia (RED), 16, 20-29.

MEDINA, O. (2000). Las condiciones de la formación laboral en la empresa. Proyecto de investigación y de intervención en el ámbito laboral. Comunicación presentada en I Jornadas de investigación en Educación de Personas Adultas. Barcelona.

MEDINA, O. DE RADA, P. GONZÁLEZ, A. (1998). Los profesionales de la for- mación en la empresa. Más allá de la frontera entre lo formal y lo no formal. En Actas del Congreso Nacional sobre la Formación del Profesorado: Evaluación y Calidad. Universidad de Las Palmas de Gran Canaria.

MEZIROW, J. (1994). Transformaciones en la educación y aprendizaje de adultos. En Sáez, J. y Palazón, F. (Coord.), La Educación de Adultos: ¿una nueva profesión?. Valencia: Nau Llibres.

MOORE, T. W. (1987). Introducción a la teoría de la educación. Madrid: Alianza.

NEUGARTEN, B. L. (Ed.) (1968). Middle age and aging: a reader in social Psychology. Chicago: University of Chicago Press.

PALACIOS, J. y MARCHESI, A. (1991). Inteligencia y memoria en el proceso de envejecimiento. En Carretero, M., Palacios, J. y Marchesi, A. (Comp.), Psicología evolutiva. Adolescencia, madurez y senectud. Madrid: Alianza.

PAPALIA, D. E. y WENDKOS, S. (1992). Desarrollo Humano. Madrid: McGraw-Hill.

PÉREZ GÓMEZ, A. I. (1998). La cultura escolar en la sociedad neoliberal. Madrid: Morata.

PETRUS, A. (1994). Educación Social y perfil del educador social. En Sáez (Coord.), El educador social. Murcia: Universidad de Murcia.

PETRUS, A. (1997). Concepto de Educación Social. En Petrus (Coord.), Pedagogía Social. Barcelona: Ariel.

REQUEJO, A. (1994). Política de educación de adultos en España. En Requejo (Coord.), Politica de educación de adultos. Santiago: Tórculo.

RICE, PH. (1997). Desarrollo humano. Estudio del ciclo vital. México: Prentice-Hall Hispanoamericana.

ROGERS, C. y FREIBERG, H. J. (1996). Libertad y creatividad en la educación. Barcelona: Paidós.

SADDINGTON (1998). Exploring the roots and branches of experiential learning. En Lifelong Learning in Europe, KVS Fundation, Finland, 3; 133-138. 
SANVISENS, A. (1983). Concepción sistémico-cibernética de la educación. En Varios, Teoría de la educación I (El problema de la educación). Murcia: Límite.

SANZ, F. (1995). Los contextos sociales en la educación de las personas adultas. En Sanz (Dir.), La formación en educación de personas adultas (Tomo 1). Madrid: UNED.

SAVATER, F. (1998). Potenciar la razón. En El Escéptico. La revista para el fomento de la razón y la ciencia, 3, 2127.

SCRIBNER, S. (1986). Thinking in action: some characteristics of practical thought". En Sternberg, R. J. y Wagner, R. K. (Edit.), Practical Intelligence. Nature and origins of competence in the everyday world. London: Cambribge University Press.

SILVESTRE, N., SOLÉ, M. R. PEREZ, M. y JODAR, M. (1996). Psicología evolutiva. Adolescencia, edad adulta y vejez. Barcelona: CEAC.

STERNBERG, R. J. (1988). La inteligencia es el autogobierno mental. En Sternberg, R. J. y Detterman, D. K., ¿Qué es la inteligencia? Enfoque actual de su naturaleza y definición. Madrid: Pirámide.

STERNBERG, R. J. y SALTER, W. (1987). Concepciones de la inteligencia. En Sternberg, R. J., Inteligencia humana, I. La naturaleza de la inteligencia y su medición. Barcelona: Paidós.

TOURAINE, A. (1993). Crítica de la modemidad. Madrid: Temas de hoy.

UNESCO (1972). Tercera Conferencia Internacional sobre Educación de Adultos. París: UNESCO.
UNESCO (1981). 19 $9^{\mathrm{a}}$ Reunión de la Conferencia General de la Unesco. Nairobi, 1976. En OEI/EDA, Reuniones internacionales mundiales sobre Educación de Adultos. Madrid: Oficina de Educación Iberoamericana.

UNESCO (1985). Cuarta Conferencia Internacional de Educación de Adultos. París: UNESCO.

UNESCO (1997a). Declaración de Hamburgo sobre la Educación de Adultos. Quinta Conferencia Internacional de Educación de Adultos (CONFITEA). En Diálogos. Educación y formación de personas adultas, 11-12, 7 .

UNESCO (1997b). Plan de acción para el futuro de la Educación de Adultos. Quinta Conferencia Internacional de Educación de Adultos (CONFITEA). En Diálogos. Educación y formación de personas adultas, 11-12, 7 .

VEGA, J. L. y BUENO, B. (1995). Desarrollo adulto $y$ envejecimiento. Madrid: Síntesis.

VERNER, C. (1964). Definition of Terms. En Jensen y otros (Comps.), Adult Education: Ourlines of an Emerging Field of University Study, Washington. En Lowe, J. (1977). La educación de adultos. Salamanca: UnescoSígueme.

VYGOTSKI, L. S. (1989). El desarrollo de los procesos psicológicos superiores. Barcelona: Crítica.

VYGOTSKI, L. S. (1995). Pensamiento y lenguaje. Barcelona: Paidós.

ZIRKEL, S. (1992). Developing independence in a life transition: Investing the self in the concerns of the day. Journal of Personality and Social Psuchology, 62, 506-521. 


\section{RESUMEN}

Se plantean en este trabajo las bases psicopedagógicas de la educación de adultos $y$, a partir de ahí, se aborda el problema del carácter específico de este sector educativo. El autor trata de defender que, basándonos en la investigación psicológica que actualmente tenemos disponible, y haciendo uso de determinados conocimientos pedagógicos, existe base para fundamentar algunos aspectos del carácter específico de la educación de adultos como un tipo de educación propia que se diferencia de lo que habitualmente se realiza en las escuelas para niños y adolescentes. En la medida en que las señas de identidad de esa educación de adultos específica son eminentemente sociales, podemos afirmar que estamos ante un campo de la educación cuyo marco teórico más amplio es el de la Pedagogía Social.

Palabras clave: Bases psicopedagógicas, carácter específico, señas sociales de identidad, marco teórico, pedagogía social.

\section{ABSTRACT}

In this work psychopedagogical bases of adult education are discussed. Further on, the question about the specific character of this educative sector is raised. The author tries to defend that, on the basis of the psychological research that is actually available, and making use of certain pedagogical wisdoms, there is a ground to lay the foundations of some aspects about the specific character of adult education as a sort of education for itself that difers from what is normally practised at school with children and teenagers. As long as the identifying marks of that specific adult education are mainly of social kind, we can state that we are in front of an educative field whose wider theoretical framework is that of Social Pedagogy.

Key words: Psychopedagogical bases, specific character, social identifying marks, theoretical framework, Social Pedagogy. 